\title{
LA ESTRATEGIA DE SEGURIDAD NACIONAL 2013: UNA EVALUACIÓN DESDE LA PERSPECTIVA DE LA PERTENENCIA DE ESPAÑA A LA UNIÓN EUROPEA
}

\author{
Mercedes Guinea ${ }^{1}$ \\ Universidad Complutense de Madrid (UCM) / UNISCI
}

\begin{abstract}
Resumen:
La segunda Estrategia de Seguridad Nacional de España (ESN) fue aprobada por el Consejo de Ministros el 31 de mayo de 2013, con la finalidad de fijar una visión global en materia de los desafíos a la seguridad y articular todas las capacidades y herramientas del Estado. España es miembro desde el 1 de enero de 1986 del sistema político multinivel que constituye la Unión Europea (UE). La seguridad nacional española no depende sólo de la actuación de sus instituciones y órganos y que debe considerar también la acción del nivel europeo. España es, además, históricamente, un Estado comprometido con la profundización política de Europa, lo que tendrá su reflejo en su marco general de seguridad. Por ello consideramos relevante analizar la dimensión europea en la ESN, desde una triple perspectiva. La primera de ellas debe valorar la pertenencia a la UE como dato objetivo que determina las condiciones de seguridad españolas. La segunda perspectiva debe considerar específicamente la UE como un espacio de acción, como un ámbito político en el cual actuar con el objetivo de incrementar nuestra seguridad. En tercer lugar, debe tenerse en cuenta la arena política e institucional europea como un instrumento más de la acción del Estado, en este caso de carácter supranacional, con la finalidad de utilizar las instituciones, políticas, capacidades e, incluso, potencialidades europeas para incrementar nuestra seguridad.
\end{abstract}

Palabras clave: España, Unión Europea, política exterior española, Estrategia de Seguridad Nacional, política de seguridad europea.

Title in English: "The National Security Strategy 2013. An evaluation from the prespective of the Spanish membership in the European Union"

Abstract:

The Spanish National Security Strategy was adopted by the Council of Ministers, on 31st May 2013. It tries to offer a global vision of Spanish security challenges in context and seeks to bring together every State capacity and tools in order to increase security. Spain is a member of the European Union since the 1st January 1986. Since the EU is a multilevel political system, Spanish national security also depends on political action and tools at the European level. Historically, Spain is committed to deepening the European political integration, which has to be reflected in its general security frame. For all these reasons, an analysis of the Spanish Security Strategy, from a specific European perspective is needed. First of all, we have to assess the fact of the Spanish membership in the European Union as a given fact that determines its security conditions. Second, we shall examine the EU as an arena for political action in order to enhance national security. Third, from an instrumental point of view, European policies and institutions should be considered also as tools at the disposal of the Spanish government. They should be employed in order to address national security concerns.

Keywords: "Spain, European Union, Spanish Foreign Policy, National Security Strategy, European Security Policy".

Copyright (C) UNISCI, 2014.

Las opiniones expresadas en estos artículos son propias de sus autores, y no reflejan necesariamente la opinión de UNISCI. The views expressed in these articles are those of the authors, and do not necessarily reflect the views of UNISCI.

\footnotetext{
${ }^{1}$ Mercedes Guinea Llorente es Profesora de Relaciones Internacionales de la Universidad Complutense de Madrid, titular del Módulo Europeo Jean Monnet de la Comisión Europea sobre "La aplicación del Tratado de Lisboa: efectos en el modelo político, económico y social". Es igualmente investigadora senior de UNISCI y miembro del Foro Hispano-Argelino.

Dirección: Departamento de Estudios Internacionales, Facultad de Ciencias Políticas y Sociología, UCM, Campus de Somosaguas, 28223 Madrid, España.

Email: mercedes.guinea@telefonica.net.
} 


\section{Consideraciones generales}

La segunda Estrategia de Seguridad Nacional de España (ESN) fue aprobada por el Consejo de Ministros el 31 de mayo de 2013, con la finalidad de definir "un marco de referencia global y omnicomprensivo en materia de seguridad", plantear "las singularidades de los riesgos y amenazas a los que nos enfrentamos", orientar la "acción del Estado (...) utilizando los recursos disponibles de forma flexible y eficaz" y potenciar "nuestras capacidades de prevención, protección y respuesta"2.

España es miembro desde el 1 de enero de 1986 del sistema político multinivel que constituye la Unión Europea (UE), con áreas donde se ha aceptado una competencia exclusiva de la UE, en otras compartida y en otras una capacidad de coordinación de políticas nacionales ${ }^{3}$. España ha sido tradicionalmente uno de los Estados más comprometidos con la profundización del proceso de integración europea, al ser uno de sus características más significativas el compromiso de la opinión pública y la totalidad de partidos políticos con el proyecto europeo ${ }^{4}$. Consecuentemente, forma parte del núcleo duro de los Estados más integracionistas, ya que participa en la práctica totalidad de los proyectos donde se han desarrollado dinámicas de diferenciación y de cooperación reforzada ${ }^{5}$.

La óptica adoptada por la ESN es la de un concepto de seguridad amplio que integra las dimensiones internas y externas ligadas a la seguridad ${ }^{6}$. A primera vista esto ya supone que la seguridad nacional española no depende sólo de la actuación de sus instituciones y órganos y que debe considerar también la acción del nivel europeo, consecuencia de pertenecer a ese sistema político multinivel. A priori, esto nos llevaría a suponer que el consenso español con el proyecto europeo también se reflejará en su marco general de seguridad. Es prioritario, por tanto, analizar separadamente cómo se contempla la dimensión europea en la ESN, si se trata de un enfoque suficiente o pueden hacerse recomendaciones de mejora.

A nuestro juicio, la dimensión europea tendría que estar presente en un instrumento político de estas características al menos desde una triple perspectiva. La primera de ellas debe valorar la pertenencia a la UE como dato objetivo que determina las condiciones de

\footnotetext{
${ }^{2}$ Introducción a "Estrategia de Seguridad Nacional" (2013).

${ }^{3}$ Existe consenso entre la comunidad científica que analiza el modelo político de la UE que ésta, debido al ejercicio de competencias soberanas de sus Estados miembros, se ha ido conformando como un sistema político multinivel que incluye a éstos, consecuencia de una integración efectiva; Ver en este sentido: Wallace, William (ed.) (1990): The Dynamics of European Integration, London - New York, Pinter; Sbragia, Alberta (ed.) (1992): Euro-Politics: Politics and Policymaking in the "New" European Community, Washington, Brooking Institution; Bulmer, Simon y Scott, Andrew (eds.) (1994): Economic and Political Integration in Europe: Integral Dynamics and Global Context, Oxford, Blackwell.

${ }^{4}$ Sobre esta cuestión: Morata Francesc (2013): "Spain: Modernization through Europeanization", en: Bulmer, Simon y Lequesne, Christian (eds.): The Member States of the European Union, Oxford, Oxford University Press, 2013, pp. 134-160.

${ }^{5}$ A mitad de 2014 pueden identificarse hasta nueve áreas sujetas a integración diferenciada, sea pactada en el nivel constitucional o por la vía de las cooperaciones reforzadas. Son el Euro, el Pacto por el Euro Plus de marzo de 2011, el Tratado de Estabilidad, Coordinación y Gobernanza, la Política Común de Seguridad y Defensa, el Acuerdo de Schengen, la Carta de Derechos Fundamentales, el Espacio de Libertad, Seguridad y Justicia, la Patente Europea y la Ley Transeuropea sobre el Divorcio. España participa en todos ellos salvo en la cooperación reforzada sobre la Patente Europea. Incluso también será parte del Impuesto sobre Transacciones Financieras, en este momento en proceso de adopción y que se ha aprobado ya como una cooperación reforzada entre diez de los Estados miembros.

${ }^{6}$ Para un análisis general de la ESN 2013, véase: Martín Cubel, Fernando: "ESN-2013: Propuesta de sistema de seguridad nacional”, Instituto Español de Estudios Estratégicos (IEEI), Documento de Opinión 118/2013 (2 de diciembre de 2013).
} 
seguridad españolas. La segunda perspectiva debe considerar específicamente la UE como un espacio de acción, como un ámbito político en el cual actuar con el objetivo de incrementar nuestra seguridad. En tercer lugar, debe considerarse la arena política e institucional europea como un instrumento más de la acción del Estado, en este caso de carácter supranacional, con la finalidad de utilizar las instituciones, políticas, capacidades e, incluso, potencialidades europeas para incrementar nuestra seguridad.

Para analizar la dimensión europea de la ESN expondremos, en primer lugar, las características de la ESN que resultan más relevantes para el análisis que desarrollaremos a continuación. Corresponde, además, preguntarse si España como miembro de la UE desarrolla en su ESN un enfoque similar, o al menos compatible, con la Estrategia Europea de Seguridad, adoptada en 2003 y revisada en 2008. En tercer lugar, nos parece relevante comparar nuestra ESN con la de otros Estados de nuestro entorno político, con el objetivo de poder extraer aprendizajes útiles. Se ha elegido para ello los de aquellos que tienen un tamaño similar e intereses comunes a los de España respecto a la UE: Reino Unido, Francia e Italia ${ }^{7}$.

A continuación pasaremos a abordar el análisis específico de cómo se contempla y se incluye a la UE en la ESN, desarrollando un análisis desde la triple perspectiva señalada anteriormente. Nuestra intención es destacar, por una parte, las insuficiencias del enfoque y, por otra, subrayar, caso por caso, los aspectos suficientes pero mejorables. A partir del análisis desarrollado se plantearán unas recomendaciones de corrección y de aplicación del documento a modo de conclusiones generales.

\section{La visión general de la ESN 2013 y la necesaria inclusión de una dimensión europea}

La ESN de 2013 responde, como ella misma afirma, a una "visión integral" de la seguridad nacional, pretende definir "un marco de referencia global y omnicomprensivo en materia de seguridad"8. Por tanto, esa visión integral exige que se tenga en cuenta la integración efectiva de España en el seno la UE, que afecta a muchos de los ámbitos de la seguridad, en la medida en que buen número de políticas se formulan en el seno de las instituciones comunes. Igualmente supone que, en la medida en que se identifiquen nuevos desafíos propios de la globalización, se dé prioridad a la cooperación en el marco europeo sobre otras vías exteriores posibles.

La ESN define la Seguridad Nacional como "la acción del Estado dirigida a proteger la libertad y el bienestar de sus ciudadanos, a garantizar la defensa de España y sus principios y valores constitucionales, así como a contribuir junto a nuestros socios y aliados a la seguridad

\footnotetext{
${ }^{7}$ En esta selección puede sorprender la ausencia de Alemania, pero hay que destacar que este Estado, aún siendo el hegemón de la Unión Europea, hasta el momento no ha aprobado ninguna Estrategia de Seguridad Nacional. Esto es atribuible, por una parte, a las particularidades del debate político interno sobre defensa y el papel de Alemania en el mundo, marcado por sus circunstancias históricas. Algunos analistas reprochan a Angela Merkel haber eludido estos temas, que hacen que Alemania descuide algunas de sus responsabilidades frente a la seguridad internacional. Véase al respecto: Dempsey. Judy: "Merkel's Surprise: A Woman in Charge of Defense", Carnegie Europe, 16 December 2013; Dempsey, Judy: "Merkel's Unfinished Bussiness: Why Germany Needs to Act Strategically", Carnegie Europe, 5 September 2013.

${ }^{8}$ Introducción a "Estrategia de Seguridad Nacional" (2013), p. I.
} 
internacional en el cumplimiento de los compromisos asumidos"9. La ESN hace una referencia indirecta a nuestros "socios", que son los Estados miembros de la UE, con quienes compartimos la responsabilidad de trabajar conjuntamente por la seguridad internacional. Se infiere que esto se hará a través de la formulación de políticas comunes en el seno de la UE, como pueden ser la Política Común de Seguridad Común (PESC) pero también otras políticas como la de Ampliación, Vecindad, Cooperación para el Desarrollo, Comercio o Migración, fundamentales para desarrollar ese enfoque onmicomprensivo de la seguridad. A nuestro juicio, la acción del Estado para garantizar la libertad y bienestar de sus ciudadanos también debe producirse a través de las instituciones comunitarias, sede de gran parte de las decisiones que afectan a la vida cotidiana de sus ciudadanos, y por tanto, a su libertad y bienestar ${ }^{10}$.

La ESN defiende la necesidad de hacer suyo un concepto de seguridad "amplio y dinámico", que aborde "todos los ámbitos concernientes a la seguridad del Estado y de sus ciudadanos" y que "abarcan desde la defensa del territorio a la estabilidad económica y financiera o la protección de las infraestructuras críticas"11. Responde, por tanto intencionalmente, a un concepto multidimensional de la seguridad, que supera el ámbito tradicional de la defensa del territorio para concentrarse en la seguridad humana de una manera omnicomprensiva abarcando tanto la "libertad frente al temor" como la "libertad frente a la necesidad"12. En ese concepto amplio de la seguridad entran, por tanto, la gran mayoría de las competencias cedidas a la UE, dentro de las cuales las decisiones y políticas comunes, repercuten de lleno en la seguridad española. Parece, por tanto, fuera de toda consideración la necesidad de tener en cuenta el nivel de decisión común y la actuación de las instituciones europeas entre los mecanismos institucionales destinados a proveer de seguridad a los españoles.

La ESN de 2013 es heredera de la de 2011 y se le asemeja en buena medida, coincidiendo ambas en esta visión amplia de la seguridad ${ }^{13}$. Aprobada al final de la segunda legislatura de Rodríguez Zapatero, en los meses más arduos de la crisis económica, no contó con el consenso del principal partido de la oposición, el Partido Popular, que anunció que la cambiaría en cuanto llegara al poder. La segunda Estrategia, ya consensuada entre los dos partidos principales constituyendo una política de Estado, se caracteriza por la continuidad con la de 2011, siendo los cambios más de forma que de fondo ${ }^{14}$.

\footnotetext{
9 "Estrategia de Seguridad Nacional" (2013), p. 1; de la lógica general del documento entendemos que existe una diferencia de concepto entre "socios" y "aliados"; los primeros son los Estados miembros de la UE, mientras que los segundos aquéllos de la OTAN.

${ }^{10}$ Un reciente estudio empírico desarrollado por el think-tank "Notre Europe" demuestra que, en torno a un tercio, de la legislación que se aplica en Francia tiene como origen el nivel legislativo europeo, sea directamente o indirectamente, esto es, a través de Directivas. Bertoncini, Yves: "Les interventions de l'UE à niveau nationale: quel impact?", Notre Europe, Études et Recherches, n 73 (Junio 2009).

11 "Estrategia de Seguridad Nacional" (2013), p. 6.

${ }^{12}$ El concepto de Seguridad Humana se exponía y desgranaba en su doble faceta, por primera vez en el "Informe sobre Desarrollo Humano" del Programa de Naciones Unidas para el Desarrollo de 1994. Véase al respecto: Kaldor, Mary (2007): Human Security, Cambridge, Polity Press; Pérez de Armiño, Karlos y Mendia Azkue, Irantzu (eds.) (2013): Seguridad humana: aportes críticos al debate teórico y político, Madrid, Tecnos; Jiménez Olmos, Javier (2013): Seguridad Internacional. Del poder militar a la seguridad humana, Zaragoza, Mira Editores.

13 "Estrategia Española de Seguridad" (2011).

${ }^{14}$ Entrevistas desarrolladas entre funcionarios nacionales dedicados a esta cuestión subrayan el carácter más participativo e inclusivo del proceso de redacción de la de 2011, donde se pidieron informes especializados a una gran cantidad de Ministerios y órganos del Estado. En cambio, la de 2013, que parece ser una actualización de la primera, fue fruto de un procedimiento de revisión circunscrito al órgano redactor.
} 
La ESN de 2011, elaborada bajo la dirección de Javier Solana, constituyó el primer intento de dotar de una visión estratégica al conjunto de la acción del Estado en materia de seguridad y presenta entre sus principales virtudes la de establecer un continuum entre las amenazas de seguridad externa e interna ${ }^{15}$. El cargo anterior que Solana desempeñara fue el de Alto Representante de la PESC de la UE. Por ello una primera impresión nos indicaría que la UE debe tener un lugar destacado y protagonista en las ESN españolas. Aquí avanzaremos parte de nuestro análisis afirmando que en ambas se hace referencia a la UE, y que en el caso de la de 2011 está más presente que en la de 2013, pero, a nuestro juicio, de una forma excesivamente reducida a la de ámbito de actuación y no en los otros dos vectores planteados más arriba. Aunque en la de 2011 se detectan más referencias a la UE, resulta igualmente insuficiente.

Estos instrumentos de política pública siguen el nuevo enfoque desarrollado desde Estados Unidos en el contexto post-11 de Septiembre y que se ha extendido por la mayor parte de los Estados de nuestro entorno ${ }^{16}$. Tienen diversas funciones entre las que destacan dar respuesta a los nuevos desafíos en materia de seguridad consecuencia del entorno complejo de la globalización, desde la globalidad, esto es, una perspectiva omnicomprensiva que incluyan todas las ramas y capacidades de un Estado. Igualmente pretenden la identificación temprana de los riesgos, intentando superar un enfoque meramente reactivo para centrarse en el preventivo y la capacidad de recuperación o resiliencia. Finalmente, constituyen una oportunidad para que el Gobierno exponga a sus ciudadanos los riesgos existentes a su seguridad y los instrumentos y capacidades con que se cuenta para enfrentarlos ${ }^{17}$. Además, la ESN trata de responder a las "insuficiencias de las estructuras y procedimientos de

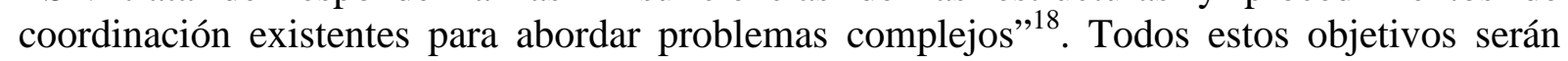
mejor servidos si se contempla adecuadamente la dimensión europea de la seguridad, en la medida en que tanto los desafíos como las respuestas a muchos de los problemas de seguridad no pueden abordarse adecuadamente sin considerar la acción política europea.

\section{3. ¿Compatibilidad o divergencias de la ESN con la Estrategia Europea de Seguridad?}

La naturaleza de un ejercicio estratégico como éste, y dado que muchos de esos desafíos derivan de las interdependencias generadas a escala europea, hacen prioritario que la seguridad se aborde también a escala de la propia UE. Esto viene reforzado por el hecho de que la UE presenta relevantes limitaciones institucionales para reaccionar con carácter

\footnotetext{
${ }^{15}$ Para un análisis de la ESN de 2011, véase: Jiménez Olmos, op. cit., pp. 127-140.

${ }^{16}$ Sobre la función de las estrategias para la seguridad de un país, véase: Arteaga, Félix (con la colaboración del Grupo de Trabajo sobre Estrategias de Seguridad Nacional del Real Instituto Elcano: "Propuesta para la Implantación de una Estrategia de Seguridad Nacional en España”, Real Instituto Elcano, Documento de Trabajo 19/2011 (16 de diciembre de 2011).

${ }^{17}$ Así en un documento de reflexión del CESEDEN sobre los motivos para elaborar una ESN se incluían: la necesidad de un enfoque sobre la seguridad unitario, coordinado y centralizado; la diversidad e importancia de los riesgos existentes; la mejor utilización del importante volumen de recursos necesarios para hacerlos frente; plasmar claramente el nivel de ambición del país; obtener sinergias entre las instituciones intervinientes; definir el papel de la industria en el conjunto; acercar a la sociedad el debate sobre seguridad; y generar consensos políticos y mayor transparencia". Centro Superior de Estudios sobre la Defensa Nacional (CESEDEN): "Hacia una estrategia de seguridad nacional para España”, Documentos de Seguridad y Defensa, no 25 (Febrero de 2009).

18 Arteaga, Félix: "La Estrategia de Seguridad Nacional 2013”, Real Instituto Elcano, Comentarios Elcano 37/2013 (31 de mayo de 2013).
} 
preventivo ${ }^{19}$. Esto es consecuencia fundamentalmente del carácter intergubernamental de la Política Exterior de Seguridad Común, que hace necesaria una decisión común por unanimidad para que la UE cuente con una política exterior propia en un ámbito determinado. En esta área política, donde no hay competencias europeas propias, la UE se comporta como una organización internacional clásica sometida a políticas intergubernamentales y, consecuentemente, las instituciones comunes carecen de competencias ejecutivas, lo que resulta inexcusable para la pro actividad y la reacción rápida.

Desde estas carencias políticas e institucionales claves se planteó la necesidad de que la UE contara con su propia Estrategia de Seguridad. El Consejo Europeo aprobó la Estrategia Europea de Seguridad (EES) en diciembre de 2003, pero no tiene exactamente la misma función que la $\mathrm{ESN}^{20}$. A primera vista puede afirmarse que la finalidad de ese instrumento estratégico sería articular y coordinar las capacidades europeas y nacionales para los desafíos comunes a la seguridad. Realmente, la función político-jurídica de este instrumento estratégico europeo es otra: consensuar las orientaciones y principios generales relativos a la acción exterior y la seguridad entre los Estados europeos, con la finalidad de que las posteriores discusiones para aprobar una decisión política concreta fueran más fáciles, al contar ya con un marco consensuado de referencia. Se trataría así de reforzar la eficacia y la rapidez de la decisión común en temas exteriores, intentando que la UE fuera un actor más proactivo.

Este documento de orientación política de la acción exterior europea se explica también a la luz de las divisiones entre Estados miembros que la UE sufrió en ese año como consecuencia de las posiciones nacionales divergentes sobre la Guerra de Irak. La EES, que salió también de la pluma de Javier Solana, entonces Alto Representante de la PESC, presentaba una concepción innovadora de una visión europea de la seguridad, que debía vertebrar la acción exterior común. Visión que se ha calificado de multidimensional o comprensiva, ya que incluye las dimensiones política, socio-económica, ecológica, cultural y militar, y cooperativa, en la medida en que pone el énfasis en el diálogo, la cooperación y la asociación ${ }^{21}$. También se ha subrayado la singularidad de un enfoque que subraya las causas de la inestabilidad, más que los efectos, y que propone para abordarlas dos recetas, multilateralismo y regulación internacional ${ }^{22}$.

En esa visión amplia o multidimensional de la seguridad coinciden tanto la EES como la ESN, no tanto en la finalidad política de los respectivos textos que es diferente. Así la EES comienza reconociendo la relevante aportación que ha constituido la creación de la UE para

\footnotetext{
${ }^{19}$ Sobre las características de la Política Exterior Común véase, entre otros: Cameron, Fraser (2012): An Introduction to European Foreign Policy, London, Routledge; Hill, Christopher y Smith, Michael (eds.) (2005): International Relations and the European Union, Oxford, Oxford University Press; Keukeleire, Stephan y McNaughtan, Jenniffer (2008): The Foreign Policy of the European Union, Basingstoke, Palgrave-Macmillan; Bretherton, Charlotte y Vogler (2006): The European Union as a global actor, London, Routledge; Cremona, Maris y De Witte, Bruno (eds.) (2008): EU Foreign Relations Law. Constitutional Fundamentals, London, Hart Publishing.

${ }^{20}$ Consejo Europeo: "Una Europa segura en un mundo mejor, Estrategia Europea de Seguridad", Bruselas (12 de diciembre de 2003); cinco años después se adoptó un Informe de actualización, que se limita a ratificar el enfoque anterior y actualizar alguno de sus extremos. Véase: Consejo Europeo: "Informe sobre la aplicación de la Estrategia Europea de Seguridad "Ofrecer seguridad en un mundo en evolución”, Bruselas (11 de diciembre de 2008).

${ }^{21}$ Biscop, Sven (2005): The European Security Strategy. A Global Agenda for Positive Power, Farnham, Ashgate, pp. 1-14.

${ }^{22}$ Aldecoa Luzárraga, Francisco: "Una Constitución para Europa y su Política Exterior Común: hacer gobernable la globalización", Real Instituto Elcano, Documento de Trabajo 1/2004 (9 de enero de 2004), pp. 24-26.
} 
conseguir paz y seguridad en Europa, pero que las amenazas a la seguridad de los Estados miembros no han desaparecido y que, por tanto, "Europa tiene que estar dispuesta a asumir su responsabilidad en el mantenimiento de la seguridad mundial y la construcción de un mundo mejor" ${ }^{23}$. Se ve, por tanto, aquí un primer objetivo del documento que es poner la base para una acción común europea y contribuir a encontrar consensos en futuras decisiones de política exterior y, especialmente, de política de seguridad, avanzando los desafíos y amenazas comunes y posibles vías de respuesta. La finalidad de la ESN es, por el contrario, acentuar la pro actividad y la acción en el mismo sentido de todas las capacidades del Estado.

Existen paralelismos en los desafíos y las amenazas que se identifican en ambas Estrategias. Así para la EES las principales amenazas son el terrorismo, la proliferación de armas de destrucción masiva, los conflictos regionales, la fragilidad de Estados y la delincuencia organizada. En el caso de la ESN se recogen todas estas amenazas, salvo la fragilidad de Estados, que se contempla como una de los ejemplos de conflictos internos que afectan al orden internacional ${ }^{24}$. La ESN, además, contempla un número más amplio de amenazas. Algunas de ellas pueden explicarse por la evolución de las interdependencias y de la realidad internacional en los diez años que separan las dos Estrategias. Otras por el hecho de que la visión europea de la seguridad, aun siendo un planteamiento de seguridad humana, es menos amplia que la de la ESN, y se ciñe al concepto más tradicional de libertad frente al temor. Igualmente hay que tener en cuenta la división institucional que existía en 2003 entre los ámbitos comunitarios y los PESC y el hecho de que la EES sólo estaba destinada a constituir el marco de referencia de ésta última.

En lo que se apartan radicalmente las dos Estrategias es en los objetivos o líneas de acción planteadas, lo que se debe a las distintas competencias que tienen ambos niveles de poder. En el caso de la EES se esbozan tres objetivos estratégicos bastante indeterminados, pero que luego resultan rellenados más bien con sugerencias de actuación. En primer lugar, bajo el imperativo título de "hacer frente a las amenazas" se encontrarían actuaciones tan diferentes como aprobar regulación europea para cooperar en materia de lucha contra el terrorismo, promover el desarrollo y la verificación de tratados internacionales que combatan la proliferación, desarrollar operaciones de gestión de crisis o, especialmente, contribuir con el arma económica a promover la democracia y el buen gobierno en terceros Estados y estabilizar y desarrollar Estados a través de la cooperación para el desarrollo ${ }^{25}$.

El segundo objetivo estratégico de la EES es "construir seguridad en los Estados vecinos" 26 . Por una parte, declara como ámbito prioritario de las políticas de seguridad europea los países situados en sus fronteras exteriores, en el Cáucaso Sur y en la cuenca mediterránea. Se plantean las bases para el desarrollo de lo que luego se conocería como Política Europea de Vecindad, que pretende la neutralización de las amenazas provenientes de estos países a través de su estabilización y la creación de interdependencias con la UE que conduciría hasta la integración económica con la misma, aplicando la noción de que el bienestar genera seguridad ${ }^{27}$. Finalmente, el tercer objetivo estratégico es la constitución de un orden internacional basado en un multilateralismo eficaz, esto es, abordar todos los

\footnotetext{
23 "Una Europa segura en un mundo mejor", op. cit., p. 1.

24 "Estrategia de Seguridad Nacional", op. cit., p. 24.

25 "Una Europa segura en un mundo mejor", op. cit., p. 6.

${ }^{26}$ Ibid., p. 7.

${ }^{27}$ En otro lugar analizábamos el objeto, la finalidad y las particularidades de la Política Europea de Vecindad. Véase: Guinea Llorente, Mercedes: "La Política Europea de Vecindad y la estabilización del entorno próximo: el caso de Europa Oriental", Revista de Derecho Comunitario Europeo, no 31 (Septiembre-Diciembre de 2008), pp. 805-831.
} 
desafíos de la gobernanza global a través de la promoción del multilateralismo y la regulación internacional $^{28}$.

La EES se plantea también el objetivo de fortalecer algunas de las estructuras institucionales de la UE, y de sus Estados miembros en algunos casos, necesario para abordar eficazmente los desafíos en materia de seguridad ${ }^{29}$. Se mencionan así el refuerzo de la dimensión proactiva de la decisión y de la política europea y de las capacidades civiles y militares que los Estados miembros ponen a disposición de la UE. Si bien en este caso se formula adecuadamente el problema, nada se articula en materia de soluciones, como resulta lógico, ya que dependen en todo caso de la voluntad política de los Estados miembros. En segundo lugar, se fija el objetivo de desarrollar políticas más coherentes, aludiendo directamente a una mejor coordinación entre políticas comunitarias y políticas PESC. En la búsqueda de la coherencia es muy relevante la aportación del Tratado de Lisboa en la medida en que prevé una institucionalidad común, de la mano del nuevo Alto Representante y el Servicio Europeo de Acción Exterior ${ }^{30}$. Finalmente, la tercera línea de acción pretende priorizar la cooperación internacional, sea bilateral o multilateral, con la finalidad de enfrentar conjuntamente las amenazas.

En conclusión, ambas Estrategias coinciden en la noción de seguridad que aplican y, parcialmente, en los desafíos y amenazas. En materia de respuestas estratégicas y adaptación política se apartan, como no puede ser de otra manera. Aquí cobra especial relevancia la diferente naturaleza de los dos actores implicados y las distintas competencias de las que ambos disponen para desarrollar sus objetivos en materia de política exterior y de seguridad. Puede, por tanto, afirmarse que ambas Estrategias son compatibles y complementarias, y que las dos sirven para reforzar, desde distintos ámbitos de acción, las posibilidades que España tiene para incrementar su seguridad.

\section{Comparación con otras estrategias nacionales de nuestro entorno}

Antes de entrar en el estudio propiamente dicho de la ESN, nos interesa abordar el análisis de la dimensión europea de las Estrategias de Seguridad Nacional de los grandes Estados de la Unión Europea con el objetivo de desarrollar un método comparativo. Hemos elegido las de los grandes Estados de la UE -Reino Unido, Italia y Francia-, dado que Alemania, como ya se ha comentado, no ha aprobado hasta este momento ningún instrumento de esta naturaleza. Nos proponemos plantear a grandes rasgos el papel que juega para estos Estados su pertenencia a la UE a la hora de formular sus políticas de seguridad, ejercicio que, necesariamente, tendrá que ser limitado y algo superficial. De su estudio, podremos extraer elementos que nos puedan ayudar para el análisis que queremos posteriormente desarrollar.

\footnotetext{
${ }^{28}$ Sobre esta cuestión puede examinarse el reciente trabajo de evaluación de las políticas multilaterales de la UE: Bouchard, Caroline, Peterson, John y Tocci, Natalie (eds.) (2014), Multilateralism in the XXIst Century: Europe's Quest for Effectiveness, Abingdon, Routledge.

29 "Una Europa segura en un mundo mejor", op. cit., pp. 12-13.

${ }^{30}$ Sobre el refuerzo de la institucionalidad común de la política exterior para reforzar la unidad, eficacia y coherencia, véase: Aldecoa Luzárraga, Francisco (Coord.) (2011): La diplomacia común europea: el servicio europeo de acción exterior, Madrid, Marcial Pons.
} 


\subsection{La Estrategia de Seguridad Nacional del Reino Unido}

En octubre de 2010, el nuevo Gobierno británico de coalición entre conservadores y liberales aprobaría su primera Estrategia de Seguridad Nacional ${ }^{31}$. Dadas la noción británica de la soberanía nacional y el peso del euroescepticismo en el seno del Partido Conservador, líder de la coalición y especialmente en la cartera de Asuntos Exteriores en manos de William Hague, no sorprende la ausencia manifiesta de la UE en su Estrategia de Seguridad ${ }^{32}$. Contra el argumento manido de que la seguridad no es una competencia transferida a la UE y por tanto no sería una referencia obligada en un texto de esta naturaleza, hay que argumentar que esta Estrategia hace suya también la visión amplia de una seguridad humana.

En este documento, que también destaca por su brevedad, vamos a encontrar escasas menciones a la UE. La mayor parte de las veces aparecerá unida a otras organizaciones internacionales como la ONU o la OTAN que sirven para que el Reino Unido, a través de su actuación proactiva, pueda disfrutar de un entorno internacional de mayor seguridad, pero no aparece como organización prioritaria. Así, por ejemplo, el prefacio firmado por los dos socios de la coalición Cameron y Clegg subraya que la defensa de los intereses británicos debe realizarse a través de la red de alianzas y relaciones, principalmente con los Estados Unidos, y, en segundo lugar, como miembro de organizaciones como la UE, la OTAN y la $\mathrm{ONU}^{33}$. En varios lugares a lo largo del texto, la propia Estrategia se referirá a la UE como parte de los instrumentos a su alcance para promover sus intereses, igualmente trazando un paralelismo con la OTAN ${ }^{34}$.

La Estrategia británica destila una visión realista de las dinámicas de organización internacional, la UE es considerada única y exclusivamente un instrumento para mejor promover los intereses británicos. Sólo va a aparecer una vez la pertenencia a la UE como elemento de definición del Reino Unido en la sociedad internacional y de forma muy acorde con la visión británica del proyecto europeo: intergubernamental y librecambista. Así, sí se menciona entre las fortalezas británicas para ser un centro económico de referencia entre Asia y América el hecho de que pertenezca al Mercado Único Europeo ${ }^{35}$.

\footnotetext{
31 "A Strong Britain in an Age of Uncertainty: the National Security Strategy", HM Government, Londres (Octubre 2010).

${ }^{32}$ Esta línea euroescéptica estallará dos años y medio después cuando Cameron, respondiendo a las tensiones dentro de su partido y al auge del eurófobo United Kingdom Independence Party (UKIP), replanteará la pertenencia del Reino Unido a la UE. Propondrá una renegociación de las competencias cedidas a la UE, con vistas a la renacionalización de algunas de ellas y la revisión de otras reglas de funcionamiento del sistema europeo. Posteriormente propone someter los resultados de estas nuevas condiciones de pertenencia a un referéndum, en el cual el pueblo británico sería llamado a decidir sobre si permanecer en la UE con las nuevas condiciones o ejercer su derecho de retirada. Ver: Cameron, David, Prime Minister: "Speech on Britain in the European Union", Londres (23 de enero del 2013).

${ }^{33}$ Literalmente afirma “... to use our unique network of alliances and relationships - principally with the United States of America, but also as a member of the European Union and NATO and a permanent member of the UN Security Council", ver: "A Strong Britain in an Age of Uncertainty", p. 4. El mismo enfoque se repite en la p. 22, en el apartado relativo al papel británico en los asuntos internacionales.

34 "This Strategy outlines the international context in which we can best pursue our interests: through a commitment to collective security (...); through an open global economy (...); and through effective and reformed international institutions including the North Atlantic Treaty Organisation (NATO), as the anchor of transatlantic security, and our vital partnership in the European Union (EU)", ver: Ibid., p. 10; en otro punto se añade: "Through NATO, the EU and other alliances we share our security needs and gain collective security benefits", ver: Ibid., p. 15.

35 "Our location and our time zone position us as a link between the economic centres of Asia and America, as well as forming part of the European single market", ver: Ibid., p. 21.
} 
La visión del Gobierno británico no lo considera un sistema político de integración del que se es parte, ni del cual dependen la mayor parte de las interdependencias que nos hacen vulnerables en la actualidad. Tampoco se tiene en cuenta el hecho de que promover una economía abierta o luchar contra el cambio climático, como se propone como línea de acción en distintos momentos de la Estrategia, dependan inexcusablemente de la acción conducida en el seno de la UE, por la falta de competencias nacionales o de capacidades críticas para detentar poder internacional ${ }^{36}$. Desde luego no sorprende que no se refiera a políticas desarrolladas en el seno de la UE cuando se alude a los instrumentos concretos que el Reino Unido puede desplegar para incrementar su seguridad y promover sus intereses en el mundo. Es coherente con la propia visión británica de sus relaciones con Europa en general y la UE en particular, y especialmente, con el marcado acento euroescéptico del Ministro al mando de las Relaciones Exteriores. No obstante, no parece que resulte muy útil una Estrategia que obvia elementos tan relevantes de la realidad que podrían ser utilizados en beneficio del interés británico como en ocasiones han propuesto otros actores políticos relevantes de la escena británica $^{37}$.

\subsection{El marco político y estratégico de la política de seguridad italiana}

Italia no ha aprobado una Estrategia de Seguridad Nacional como tal, pero su Directiva para una política militar contiene una descripción detallada del entorno político y estratégico, y su análisis puede ayudarnos para desvelar las fortalezas y debilidades de nuestra $\mathrm{ESN}^{38}$. Al realizar la comparación, en cualquier caso, tendremos que tomar nota de las diferencias entre la finalidad de una Directiva militar, que pretende servir de referencia para la organización de las capacidades militares exclusivamente, y una Estrategia de Seguridad, llamada a articular de forma coordinada todas las capacidades del Estado. El análisis de la Directiva italiana incide fundamentalmente en dos dimensiones de la seguridad: la seguridad internacional "clásica" amenazada por la desestabilización de terceros y la seguridad económica y financiera.

De la Directiva italiana llama la atención que el país se considere a sí mismo como parte tanto de la UE y de la OTAN, siendo por tanto para Italia la pertenencia a la UE un elemento definitorio de su identidad y de su lugar en el mundo ${ }^{39}$. Tal y como aparece en la Directiva, la UE es el punto de referencia para el análisis de la seguridad italiana tanto en términos económicos como de seguridad clásica. En este último ámbito se alude igualmente a la OTAN. Por el contrario, hay escasas por no decir ninguna referencia a sí mismo como Estado actuando independientemente en materia de seguridad. En ese sentido, reconoce claramente

\footnotetext{
${ }^{36}$ Véase a título de ejemplo la p. 18 de la ESN 2013.

${ }^{37}$ En este sentido, llamaríamos la atención sobre diversos Informes de la Cámara de los Lores que abogan porque el Reino Unido aproveche las estructuras de cooperación de la política de defensa europeas en tanto le resulte de provecho tanto en términos políticos como económicos e industriales; ver: House of Lords, European Union Committee: "European Defence Capabilities: lessons from the past, signposts for the future", Londres (2012).

38 "Ministerial Directive on the military policy for the year 2013", Ministerio Italiano de Defensa, Roma (2013).

${ }^{39} \mathrm{Al}$ describir y analizar el contexto internacional de referencia en ningún momento se alude a Italia sino al marco de la Unión Europea como referente para el cual evaluar la seguridad. En este sentido, termina ese epígrafe afirmando "European Union countries should not overlook these developments, otherwise they will be progressively marginalized and their influence on the world scenario will decline while they will become increasingly permeable to destabilizing factors originated within other world regions". "Ministerial Directive on the military policy for the year 2013", op. cit., p. 6.
} 
las limitaciones italianas como actor independiente de la seguridad y la defensa y el hecho de la fortaleza que supone la pertenencia a estas organizaciones/sistemas políticos ${ }^{40}$.

En este contexto, la UE tiene un protagonismo relevante, tanto como elemento para describir el entorno de seguridad de Italia, como ámbito de acción y como instrumento para reforzar la seguridad italiana. En el primer sentido, la descripción del contexto de seguridad internacional, la Directiva comienza enumerando la contribución de la UE a la seguridad del continente europeo, tanto a través de su proyecto de reconciliación de enemigos como a través de la estabilización conseguida por su política de ampliación, todavía abierta a nuevos Estados del continente ${ }^{41}$. Va a aludir tanto a la UE como a la OTAN como instrumentos para estabilizar las regiones vecinas que amenazan la seguridad italiana, a través de una variedad de instrumentos que apoyen la democratización y gobernanza de estos países. Igualmente atribuye a ambas organizaciones la responsabilidad de llevar a cabo una relación especial con Rusia, actor relevante de la seguridad internacional. Termina su valoración del entorno de seguridad alertando sobre el peligro de que los miembros de la UE sean complacientes sobre sus aportaciones a la seguridad y no presten suficiente atención a las nuevas dinámicas del sistema internacional, lo que puede marginarlos y exponerlos crecientemente a desestabilizaciones provenientes de otras regiones.

En relación a las áreas de acción, en el ámbito de la seguridad europea, la Directiva señala los avances en la integración que está sufriendo en la actualidad la UE derivados del Tratado de Lisboa, de la mayor gobernanza económica consecuencia de la crisis y de la creciente asunción de misiones internacionales en el marco de la PCSD. No obstante, se reconoce que para que la UE pueda estar a la altura de las demandas en materia de gestión de crisis, generadas por la ambición de su política global, los Estados miembros deben profundizar su cooperación en los ámbitos de seguridad y defensa ${ }^{42}$. Se entiende, aunque no lo diga, que Italia apoyaría este desarrollo de la PCSD. En relación al marco económico y financiero, la Directiva reflexiona sobre las causas de la crisis del euro, detalla los mecanismos, y normativas adoptados en el seno de las instituciones comunes para abordar los desequilibrios que amenazaban al euro. El Gobierno italiano se declara comprometido con los objetivos de la integridad de la eurozona, del refuerzo de la coordinación de las políticas económicas y de la estabilidad financiera ${ }^{43}$.

En el plano de las actuaciones para incrementar la seguridad internacional, se subraya el compromiso italiano en seguir contribuyendo a la gestión de crisis internacional a través de la UE y la OTAN. Se reafirma contundentemente la importancia de la estabilidad económica y financiera no sólo para la propia UE sino para el conjunto del sistema internacional y, por ello, el decidido compromiso italiano con asegurar la estabilidad de la moneda única en el largo plazo. En coherencia con toda la línea de la Directiva se afirma "El respeto absoluto de nuestros compromisos en la UE es un elemento fundamental de nuestra política nacional"44. Se compromete consecuentemente con las reducciones del déficit público y deuda pública señaladas por las autoridades europeas como condición esencial para definir las opciones de su política de defensa.

\footnotetext{
${ }^{40}$ Así afirma taxativamente: "Italy, similarly to other European countries, will not be able to pursue its political goals in the field of defence policy on a strictly national plan. On the contrary, closer and closer cooperation with NATO allies and European partners must become a fundamental element of our national policy", ver en: "Ministerial Directive on the military policy for the year 2013", op. cit., p. 11.

${ }^{41}$ Ibid., pp. 3-5.

${ }^{42}$ Ibid., p. 6.

${ }^{43}$ Ibid., p. 7.

${ }^{44}$ Ibid., p. 8.
} 
En el plano específico de las capacidades de defensa, se reconoce que Italia por su cuenta no es capaz de desarrollar sobre una base nacional sus objetivos políticos y que la cooperación en el seno de la UE y la OTAN es un elemento fundamental de la política nacional. Por ello, establece que el desarrollo de sus capacidades debe ser coherente con las directrices de estas dos organizaciones y explotarse al máximo las oportunidades que los enfoques del "Pooling \& Sharing" de la UE y la "Smart Defence" de la OTAN ofrecen para transformar las fuerzas militares en un instrumento apto para enfrentar los desafíos actuales. Por si hubiera dudas sobre la implicación italiana en la política europea y en como considera que la cooperación europea debe ser el instrumento de referencia para incrementar la seguridad italiana, el documento apoya abiertamente que el objetivo final debe ser la integración de las políticas de defensa de todos los Estados miembros a través de una armonización gradual y en coherencia y sinergia con la OTAN ${ }^{45}$. En paralelo apoya abiertamente el desarrollo de la cooperación europea en las industrias de defensa y las capacidades tecnológicas para apoyar esta integración de las capacidades de defensa y mejorar las operaciones multinacionales de gestión de crisis.

Para la seguridad italiana, la integración europea es la referencia, apoyándose explícitamente el desarrollo de una Política Europea de Defensa, que es para ellos, el único camino para que Italia pueda contar con un sistema de defensa efectivo y adecuado a los actuales desafíos en materia internacional. Nos encontramos, por tanto, en la visión opuesta de la Estrategia británica, en la medida en que se plantea el presente y el futuro de la seguridad italiana en el marco de la integración europea, para la cual se apoya explícitamente su desarrollo político.

\subsection{El Libro Blanco de Defensa y Seguridad Nacional de Francia}

En el año 2013, cinco años después de la anterior, el Gobierno francés de François Hollande aprobaba su Libro Blanco de Defensa y Seguridad Nacional, documento de estrategia para articular todas las capacidades nacionales para reforzar la seguridad francesa ${ }^{46}$. Tiene, por tanto, el mismo alcance y ambición que el español, aunque responda a otra denominación y sea mucho más largo y prolijo en su análisis ${ }^{47}$. Como el español, reflexiona en el entorno de seguridad de Francia y cuáles deben ser los fundamentos de la seguridad francesa, analiza el estado del mundo, las prioridades estratégicas y los medios o instrumentos para conseguir esos objetivos. Tiene algunos capítulos más, que no encuentran correlación en el español, entre los cuales destacaríamos el quinto, relativo al compromiso de Francia en la OTAN y en la UE, capítulo de importancia central para nuestro análisis.

\footnotetext{
45 "The final goal must be the integration of the defence policies of the European countries, to be implemented through the gradual harmonization of their Force planning processes and military requirements. The capability development process enacted within the framework of NATO and the EU must also be harmonized concurrently. Italy, a member of both institutions from their very beginning, must concretely boost synergies between them. European countries will not be able to make significant steps forward in terms of operational capabilities and autonomy of action without a clear synergic commitment that can function as the basis for future integration in the field of security and defence policies", ver en Ibid., p. 11.

46 "Livre blanc de la Défense et Sécurité Nationale", Ministerio Francés de Defensa, París (2013).

${ }^{47}$ En un análisis comparativo de ambos documentos se ha destacado que ambas Estrategias comparten muchos puntos en común como una visión análoga del mundo, en la noción amplia y multidimensional de la seguridad y en la determinación de asumir los compromisos internacionales. Se subrayan que las diferencias, fruto de la historia y de la cultura política de ambos Estados, son fundamentalmente tres: la disuasión nuclear, la arquitectura nacional de seguridad y el papel que se otorga en las Estrategia al planeamiento de las Fuerzas Armadas para asegurar la defensa nacional. Véase a este respecto: Laborie, Iglesias, Mario: "Las Estrategias de Seguridad Nacional de Francia y España: un análisis comparado”, Instituto Español de Estudios Estratégicos (IEEE), Documento de Análisis, 42/2013 (12 de julio de 2013).
} 
A nuestro juicio, la estrategia francesa es la que trata de manera más completa la dimensión europea, en la medida en que desarrolla el triple vector. Analiza su situación y rol en el mundo desde la realidad de su integración en la UE, integra las necesidades de la seguridad europea en sus prioridades estratégicas y las traduce en un proyecto político para el futuro europeo y se sirve de las políticas, medios e instrumentos europeos para incrementar su propia seguridad. Esta dimensión europea se encuentra presente, incluso, en el propio equipo redactor, que cuenta con un alemán y un británico y con un representante de la UE, junto con los miembros del Gobierno francés en calidad de expertos ${ }^{48}$. Siendo un trabajo concienzudo, largo y prolijo, de 160 páginas, aquí sólo podemos resumir y comentar algunos de sus aspectos más significativos.

En primer lugar, el aspecto más reseñable es el hecho de que Francia se define, desde los primeros párrafos, como una potencia europea, haciendo de la UE el elemento de referencia de su posición internacional ${ }^{49}$. Se subraya la aportación del proceso de integración europea a la paz y seguridad del continente europeo, y especialmente de Francia ${ }^{50}$. Esto puede explicarse incluso como reivindicación de la aportación francesa al proyecto, que encuentra sus orígenes en la proposición del Ministro francés Schuman y el original plan político de Monnet.

Se reconoce igualmente que la función de la UE para sus Estados miembros en nuestros días no es otro que permitirles conservar el control de su destino en el entorno de la globalización $^{51}$. Por todo ello, se contempla la seguridad francesa de manera simbiótica con la seguridad europea, que sólo podrá fortalecerse a través de la continuación del proceso de integración ${ }^{52}$. Se parte de la idea de que Francia es parte de la "comunidad de destino" que es la UE, y todo el Libro Blanco desarrollará este enfoque, entendiendo los desafíos a la seguridad francesa, las estrategias necesarias y las capacidades a construir como aquellos que afectan de igual manera a la seguridad europea.

De hecho se afirma que las nuevas demandas que enfrenta la UE en materia de seguridad dan una razón suplementaria a Francia para que preste una atención especial al desarrollo de sus capacidades nacionales. Recuerda que esa responsabilidad que debe asumir la UE en su seguridad y en la seguridad internacional apela a la necesidad de una mayor

\footnotetext{
${ }^{48}$ Bajo la Presidencia de Jean-Marie Guéhenno, la Comisión redactora reunió a representantes del Parlamento, de los distintos Ministerios y un conjunto de expertos. Entre ellos destacan representantes de instituciones europeas como es el caso de Claude-France Arnould, Directora Ejecutiva de la Agencia Europea de Defensa; Wolfgang Ischinger, alemán, Presidente de la Conferencia de Munich para la Seguridad, y Peter Ricketts, británico, Embajador del Reino Unido ante Francia.

49 Así, el primer epígrafe relativo a la descripción del entorno internacional de seguridad se titula muy significativamente "La France, puissance européenne, au rayonnement global", ver en "Livre blanc de la Défense", op. cit., p. 13.

${ }^{50}$ Se comienza recordando la importancia de la aportación del proyecto europeo a las condiciones de paz y seguridad de Francia, de Europa y de mundo. "Elle fait partie d'un ensemble politique, l'Union européenne, qui a rendu impensable la perspective d'un conflit dans son sein (...) Aujourd'hui, l'Europe concourt à la sécurité collective en intervenant à la gestion de crises régionales. Elle le fait en promouvant des valeurs qui ont une portée universelle", en Ibid., Idem.

51 “En ouvrant à ses membres la possibilité de forger ensemble les conditions d'un avenir partagé, l'Union européenne conforte leur capacité de conserver la maîtrise de leur destin dans l'environnement de la mondialisation", ver en Ibid., p. 16.

52 “La réussite interne de l'Union constitue non seulement une clé de l'avenir politique et économique de la France mais aussi un fondement essentiel de sa sécurité, en contribuant à construire un monde que corresponde à ses valeurs (...) C'est dans cette perspective qui constitue pour elle un objectif essentiel, que la France conçoit son avenir et l'exercice de sa souveraineté", ver en Ibid., p. 17.
} 
cooperación de todos los Estados miembros ${ }^{53}$. Plantea igualmente su propia estrategia de seguridad como instrumento a partir del cual construir con el resto de Estados miembros un diálogo profundo sobre la gestión de las interdependencias mutuas.

En segundo lugar, el Libro Blanco establece la posición francesa frente a la profundización europea que se está produciendo en nuestros días como consecuencia de la crisis y cuál ha de ser la función europea en la seguridad internacional. Se valora así cómo los efectos de la crisis han recortado la influencia internacional de la UE y cómo este hecho expone a la UE y a Francia a una situación de mayor vulnerabilidad ${ }^{54}$. En esta dimensión de la UE como ámbito de acción, se realiza un análisis frío y acertado de cuáles son los desafíos que hoy amenazan al proyecto europeo, tanto respecto a la profundización de la Unión Económica y Monetaria como del necesario progreso en materia de cooperación en seguridad y defensa ${ }^{55}$. Se afirma en relación a estos dos desafíos una posición integracionista, que persigue negociar y trabajar por el incremento de la cesión de soberanía y la profundización de la Unión Política. Para Francia la mejor estrategia para incrementar su seguridad e influencia internacional pasa por el fortalecimiento de la UE, para el cual esboza su proyecto y considera que este modelo de "interdependencias organizadas" es la mejor garantía para una UE y un mundo más seguros ${ }^{56}$.

En esta dimensión de la UE como ámbito de acción, el Libro Blanco apuesta decididamente por la opción de una defensa europea integrada, eficaz y creíble, en paralelo a una cooperación más amplia en el seno de la OTAN, que se entiende como no concurrente sino complementaria ${ }^{57}$. No es ingenua, sin embargo, respecto a las dificultades para progresar en su consecución ${ }^{58}$. El Libro Blanco recoge en su capítulo quinto una verdadera agenda para el desarrollo futuro de la Política Común de Seguridad y Defensa, que considera una prioridad absoluta para Francia, convencida de que "una respuesta europea será superior a la suma de respuestas nacionales" y más en el contexto de crisis, que limita la inversión nacional en capacidades de defensa ${ }^{59}$. Justifica la necesidad de desarrollar esta integración reivindicando la necesidad de capacidades "duras" de defensa si "Europa no quiere quedarse fuera del juego de los Estados poderosos y contribuir a la constitución de un orden internacional más estable"60.

En el ámbito de la PCSD, llama la atención sobre la necesidad de actuar preventivamente para evitar crisis en la vecindad, mejorar aspectos sustanciales para el desarrollo de misiones de gestión de crisis $y$, finalmente, cooperar en materia de capacidades $^{61}$. En este sentido, resulta especialmente significativa la reflexión que se hace sobre la necesidad de incrementar los acuerdos bilaterales o multilaterales entre algunos de los Estados miembros como vía para avanzar la cooperación europea en materia de capacidades

\footnotetext{
53 “L'évolution du contexte géopolitique, économique et budgétaire commande d'approfondir le développement volontariste de convergences stratégiques entre Européens”, ver en Ibid., p. 22.

54 "Les conséquences stratégiques de ces évolutions affectent en profondeur les conditions de la sécurité de la France et de ses partenaires de l'Union européenne. Si le spectre d'une conflagration majeure née en Europe s'est éloigné, les Européens ne peuvent ignorer le monde instable qui les entoure et auquel ils sont indissolublement liés", ver en Ibid., p. 32.

${ }_{55}^{55}$ Véase al respecto el análisis desarrollando en las páginas 30 a 33.

${ }^{56}$ Ibid., p. 39.

${ }^{57}$ Ibid., p. 63.

58 "La France réaffirme son ambition en faveur d'une défense européenne crédible et efficace, mais elle ne saurait ignorer les difficultés auxquelles se heurte le développement du cadre européen”, ver en Ibid., p. 61.

${ }^{59}$ Ibid., p. 64.

${ }^{60}$ Ibid., p. 65.

${ }^{61}$ Ver Ibid., pp. 65 a 68 y pp. 97-100.
} 
de defensa, evitar duplicidades y colmar lagunas. Se defienden estos partenariados intergubernamentales, por la dificultad de avanzar entre todos los Estados miembros, por las diferencias conceptuales existentes y se afirma que son compatibles con las iniciativas multilaterales desarrolladas en el seno de la UE. En paralelo se apoya la idea de profundizar también la cooperación para el refuerzo de la capacidad industrial europea en materia de desarrollo tecnológico y competitividad internacional.

En tercer lugar, la Estrategia francesa considera a la UE como un instrumento para incrementar la seguridad francesa y reforzar la posición francesa en el mundo. Así tanto en la evaluación de los desafíos como en las prioridades estratégicas, junto al análisis de la posición francesa se encuentra también la europea, barajándose las dos dimensiones en paralelo. De incluso, entre las prioridades estratégicas, las número dos y tres se refieren específicamente a la dimensión europea de la seguridad: garantizar con los socios y aliados la seguridad de Europa y del espacio nord-atlántico y estabilizar con nuestros socios y aliados la vecindad europea $^{62}$. En el marco de la primera prioridad estratégica, la puramente nacional de defender el territorio y a los nacionales franceses, frente a amenazas como los ciberataques o las necesidades de evacuación de urgencia se alude a la aportación de la cooperación entre Estados europeos $^{63}$.

Desde el punto de vista de los instrumentos europeos para incrementar la seguridad de los Estados miembros, el Libro Blanco recuerda muy acertadamente la importante contribución que el Tratado de Lisboa presenta para la seguridad de los Estados miembros a través de la cláusula de asistencia mutua y la cláusula de solidaridad, que supone la respuesta de todos los Estados miembros en caso de que uno de ellos sufra un ataque armado, un ataque terrorista o una catástrofe de origen natural o humano ${ }^{64}$. Igualmente se subraya la importancia que el Programa de Estocolmo, de lucha contra el terrorismo y la criminalidad, tiene para afrontar los desafíos a la seguridad interior ${ }^{65}$. En el ámbito de los desafíos presentados por la vecindad europea, se alude de distintas maneras a la necesidad de una política europea común para garantizar la seguridad francesa y europea en las relaciones con países como Rusia, Turquía, los del Mediterráneo, los del Sahel o los de Europa Oriental, subrayándose la necesidad de encontrar una visión europea común para abordar de manera concertada los desafíos procedentes de estas zonas ${ }^{66}$. En este sentido, la estrategia de seguridad francesa quiere en buena medida contribuir con su reflexión a una estrategia europea que tiene pendiente su actualización.

No toda la estrategia presenta una instrumentación igual de la dimensión UE para construir seguridad en Francia. Así sorprende que en la contribución de la paz en el mundo, al referirse a las relaciones con algunos actores internacionales, no haya una sola mención a la UE, como es el caso de Asia del Sur, China, Japón, o América Latina ${ }^{67}$. Esta ruptura con la tendencia anterior es doblemente reseñable, dado que lo principal de las relaciones con estos países es de naturaleza comercial, cuya competencia exclusiva pertenece a la UE.

\footnotetext{
${ }^{62}$ Así, las prioridades que se establecen son: “- protéger le territoire national et les ressortissants français, et garantir la continuité des fonctions essentielles de la Nation;

- garantir avec nos partenaires et alliés la sécurité de l'Europe et de l'espace nord-atlantique;

- stabiliser avec nos partenaires et alliés les approches de l'Europe;

- participer à la stabilité du Proche-Orient et du Golfe Arabo-Persique;

- contribuer à la paix dans le monde”, ver en Ibid., pp. 47-59.

${ }^{63}$ Ibid., p. 51.

${ }^{64}$ Ibid., p. 52.

${ }^{65}$ Ibid., p. 53.

${ }^{66}$ Ibid., pp. 53-56.

${ }^{67}$ Ibid., pp. 56-59.
} 
En relación a la implementación de la estrategia para incrementar la seguridad, también en numerosos apartados se refiere a la cooperación europea como medio para incrementar la seguridad europea como es el caso de las capacidades espaciales y de satélites en materia de inteligencia, la cooperación europea para responder a los ataques a capacidades críticas o a la seguridad marítima ${ }^{68}$. La misma alusión a la acción normativa europea se hace al referirse a las amenazas medioambientales o las relativas a la salud humana, al igual que a la importante contribución de la UE en materia de consolidación de la paz, para la que está especialmente bien dotada por el abanico de instrumentos de los que dispone. Se subraya igualmente la distinta aportación que la UE y sus Estados miembros puede presentar en ámbitos tan diferentes como el análisis del riesgo, la protección del territorio y de los espacios marítimo y aéreo, la lucha contra el terrorismo, las ciberamenazas, la proliferación, el narcotráfico y el tráfico de personas, la capacidad del Estado de responder a las crisis.

En conclusión, el Libro Blanco francés constituye, de todas las estrategias analizadas, la más perfeccionada en lo que atañe a la dimensión europea de la seguridad. Define la seguridad francesa en unión con la europea, y desarrolla coherentemente este enfoque tanto en relación con el compromiso francés de desarrollar la PCSD para mejorar la defensa francesa como en el recuento de la aportación de la UE como instrumento para incrementar la seguridad francesa. Constituye, por tanto, un buen modelo para contrastar la ESN de 2013.

\section{La Unión Europea en la Estrategia Nacional de Seguridad: Un análisis transversal}

En la ESN de 2013 vamos a analizar a lo largo de todo el texto los tres vectores señalados relativos a la dimensión europea de la seguridad nacional. En primer lugar, se tendrá en cuenta las implicaciones de la pertenencia a la UE en la definición de la situación objetiva de España en materia de seguridad. Segundo, se estudiará cómo se considera la UE como ámbito de acción específico con el objetivo de incrementar nuestra seguridad. En tercer lugar, se examinará en cada una de las líneas de acción establecidas en qué medida se considera la pertenencia a la UE y las políticas desarrolladas en su seno como instrumentos para incrementar y reforzar nuestra seguridad.

\subsection{La pertenencia a la UE y la seguridad española}

La presentación del Presidente del Gobierno, Mariano Rajoy, comienza la introducción de la Estrategia presentando a España como "país mediterráneo miembro de la Unión Europea, con una posición geográfica privilegiada al tiempo que compleja, tiene un perfil nítido y propio" $^{69}$. La pertenencia a la UE sólo sirve a efectos descriptivos, pero no se tienen suficientemente en cuenta sus implicaciones políticas. Así en el capítulo I, donde se propone una visión integral de la Seguridad Nacional, sorprende que no se aluda en ningún momento a la UE, ni a ninguna de sus estructuras ni políticas, como elementos que definen y condicionan la seguridad española ${ }^{70}$.

\footnotetext{
${ }^{68}$ Ibid., pp. 87-112.

${ }^{69}$ Introducción en "Estrategia de Seguridad Nacional", (2013), p. 1.

${ }^{70}$ Ibid., pp. 5-9.
} 
Al hablar del nuevo entorno internacional, en varios lugares se hace referencia a la naturaleza transnacional de algunos de los nuevos riesgos y amenazas ${ }^{71}$. Más allá de esa generalidad, la UE no se tiene en cuenta como un elemento determinante de esa transnacionalidad creciente. Indudablemente la integración producida en el seno de la UE tiene como consecuencia la emergencia de nuevos riesgos y amenazas, o la escalada cualitativa de otros que se darían igual. Así, a título de ejemplo, a nuestro juicio las presiones migratorias en nuestra frontera Sur serían otras de no ser nuestro país miembro de la UE y el alcance de la crisis económica diferente de no pertenecer al euro.

En ese primer capítulo de la ESN, se afirma que la respuesta a riesgos y amenazas precisa "de la cooperación nacional y multilateral y la acción conjunta", aunque luego veremos no se integra ese enfoque multilateral en las estrategias para construir seguridad nacional $^{72}$. Entre los nuevos ámbitos donde se juega la seguridad del Estado se alude en varias ocasiones a la estabilidad económica y financiera, sin aludir a la UE, lo que resulta un absurdo, ya que de ella depende fundamentalmente la citada estabilidad ${ }^{73}$. Resulta llamativo que se señale expresamente que la crisis económica y financiera es uno de los mayores retos, se afirma que afecta a España, al euro y a otras economías desarrolladas. No se menciona la pertenencia a la UEM como uno de los factores fundamentales de la crisis y, desde el cual deben provenir las respuestas. No existe ninguna alusión a los principales defectos de construcción de la Eurozona, que explican la especificidad de la crisis del euro y de sus Estados miembros. La acción para resolver tanto los elementos coyunturales de esta crisis como para prevenir futuras claramente sólo podrá proceder de la acción conjunta de la Eurozona, algo que la ESN ni menciona, como sí hacían tanto la estrategia italiana como la francesa. Corresponde a España como Estado miembro contribuir desde las instituciones del nivel europeo a encontrar respuestas para remediar los defectos de diseño de una UEM incompleta.

El final de este capítulo detalla el alcance que tiene la Seguridad Nacional como Política de Estado y cuáles deben de ser los principios informadores de la Estrategia. Aquí de nuevo no se encuentra ninguna alusión al nivel europeo. Así, por ejemplo, la unidad de acción se entiende de "todos los actores y los recursos del Estado" pero no se extiende al nivel supranacional, cuya asistencia debería integrarse para abordar adecuadamente los retos de $\operatorname{seguridad}^{74}$.

\subsection{La Unión Europea como ámbito de acción}

En el Capítulo 2, relativo a la "Seguridad de España en el mundo", se identifican los entornos estratégicos para España en un orden global en redefinición. Así se afirma que "Europa y el Mediterráneo son nuestras grandes prioridades estratégicas. El futuro de España, la seguridad y el bienestar de sus ciudadanos están ligados en gran medida, a la evolución de esas regiones"75. Es absolutamente desmedido e inadecuado poner las repercusiones para la seguridad española de estas dos regiones en pie de igualdad, incluso si no estableciéramos la equiparación entre Europa y la UE. La evolución del Mediterráneo puede afectarnos por su capacidad para generar desestabilización y transmitir a España riesgos como presiones migratorias, crimen organizado, terrorismo, seguridad en los suministros energéticos, etc. En el mismo sentido podría entenderse la desestabilización producida por los tres países de

\footnotetext{
${ }^{71}$ Véase a título de ejemplo: Ibid., p. 6.

${ }^{72}$ Ibid., Idem.

${ }^{73}$ Ibid., Idem.

${ }^{74}$ Ibid., p. 9.

${ }^{75}$ Ibid., p. 12.
} 
Europa Oriental o del Cáucaso Sur que son objeto de la Política Europea de Vecindad. No es previsible, por el contrario, esperar tensiones de otros países de Europa, dada las profundas interdependencias existentes, o bien por la integración económica o por su vinculación a partir de la Política de Preadhesión.

La realidad de la integración europea, por el contrario, ha ligado nuestro destino en ámbitos económicos, políticos y sociales al de la UE. La acción inadecuada o inacción europea en materias donde se hayan cedido competencias afectan directamente a las políticas que pueda desarrollar el Estado, como ha puesto de manifiesto dolorosamente la crisis. La seguridad y el bienestar de los ciudadanos españoles dependen, por tanto, de la acción política europea en algunas áreas como pueden ser la economía, la seguridad alimentaria o las relaciones comerciales, en mucha mayor medida que del nivel estatal, que ya carece de competencias y autonomía en su actuación.

Resulta, por tanto, fundamental integrar el nivel de decisión europeo en las estrategias del Estado para construir seguridad. En un momento dado, esa acción consistirá en movilizar todos los recursos al alcance del Estado en las instituciones comunes para promover una decisión política o legislativa que se acomode a los intereses españoles. Esa actuación implica necesariamente la presentación de una posición coherente entre todos los representantes gubernamentales españoles, lo que no siempre se ha dado en el caso de los últimos Gobiernos $^{76}$. Para ello resulta fundamental el refuerzo de la coordinación de todas las capacidades gubernamentales de España, antaño ejercida desde la Secretaría de Estado de la UE, y cada vez más desdibujada por el auge de la diplomacia personalista de los distintos Ministros y la mayor facilidad del contacto directo. También implica actuaciones eficaces ante los representantes españoles en otras instituciones europeas (Parlamento Europeo, Comisión, Comités...) de forma que se promueva una defensa coherente de los intereses españoles.

La ESN concluye con un capítulo dedicado a la creación de un nuevo "Sistema de Seguridad Nacional", que se apoya en varios principios como la dirección política del Presidente del Gobierno, el funcionamiento integrado y coordinado de todas las Administraciones Públicas con competencia en materia de Seguridad Nacional y la optimización de los recursos disponibles ${ }^{77}$. Sorprende que en esa nueva arquitectura, especialmente en el Consejo de Seguridad Nacional, no aparezcan específicamente personas encargadas de coordinar la acción nacional con la actuación europea. La integración de la dimensión europea y la defensa de nuestros intereses en esas estructuras implicaría la necesidad de contar al menos con el Secretario de Estado para la UE, con la finalidad de que active y coordine a los representantes españoles en las instituciones europeas. En la medida en que una de las funciones de ese Consejo de Seguridad es "dirigir y coordinar la gestión de crisis", y que la mayor parte de las operaciones de esta naturaleza en las que participa España son operaciones de la UE, parece imprescindible articular alguna forma de contacto y de implicación del SEAE en el Sistema de Seguridad Nacional con la finalidad de lograr esa coordinación $^{78}$. Esa relación podría asegurarse mediante la participación en el Sistema del representante español en el Comité Político y de Seguridad de la UE.

\footnotetext{
${ }^{76}$ Véanse algunos ejemplos de actuación incoherente de las distintas ramas de la Administración española en: Guinea Llorente, Mercedes: "España en la Política Exterior Común europea: los últimos diez años (2001-2011)", UNISCI Discusión Papers, no 27 (Octubre 2011).

77 "Estrategia de Seguridad Nacional", (2013), pp. 53-58.

${ }^{78}$ Ibid., p. 56.
} 
El segundo vector clave de una estrategia de seguridad es el proyecto de Unión Europea a promover desde el Estado para incrementar su seguridad y defender sus intereses. En este sentido, la ESN de 2013 comienza el apartado dedicado a la UE con una afirmación rotunda y parece que comprometida: "Avanzar en la construcción europea es hacer a España más segura y próspera" ${ }^{79}$. Se afirma, además, la necesidad de reforzar a la UE en su plano interno y su dimensión exterior, fortalecer la UEM y afianzar la Unión Política, al ser "un factor determinante para nuestra seguridad".

Este compromiso con la profundización del proyecto europeo destaca por su carácter ambiguo e indeterminado. Sorprende desde luego que no se haga ninguna mención a los enormes desafíos que enfrenta la UE en el momento de redacción de la ESN, como en cambio sí hacían aunque limitadamente las estrategias italiana y francesa estudiadas. Es un contexto en que casi se enfrenta a una crisis existencial, tanto por el riesgo de ruptura del euro, como por las diferencias crecientes entre los Estados miembros, que se reflejan en muchas de sus decisiones políticas, y la creciente desafección, por no decir, rechazo de la ciudadanía europea. No existe ninguna mención a la profunda transformación que está experimentando la UE como consecuencia de la crisis, transformación caracterizada por una profundización relevante de la Unión Económica pero sólo en el nivel de la Eurozona y a través de formulas de gobernanza tecnocrática que plantean importantes preocupaciones desde el punto de vista de la legitimidad ${ }^{80}$.

Es destacable que no se plantee ninguna visión de futuro para el proyecto europeo, aunque sea definida en sus aspectos más básicos, como sí hacen las estrategias francesa e italiana, en un momento en el que existe un consenso suficiente en la sede europea sobre la necesidad de abordar una profundización ambiciosa tan pronto como sea posible tras las elecciones de 2014. Sabemos que es cuestión de meses o de dos años a lo sumo pero que una profunda revisión de los Tratados se avecina. Y, sin embargo, el Gobierno español comparte el proyecto de construcción política de la UE y es un proyecto de consenso entre las principales fuerzas políticas españolas.

El Gobierno español ha sido un actor activo en el debate europeo, formando parte del conocido como Grupo sobre el Futuro de Europa ${ }^{81}$. Este Grupo ha planteado un ambicioso plan de profundización en la línea federalista, en torno a una serie de objetivos: la construcción de una Unión Económica como contrapeso a la Monetaria, una forma institucional que prime la capacidad de acción del nivel europeo y una rendición de cuentas democrática, y la mejora de las estructuras para reforzar el perfil internacional de la UE. Aunque no tenemos aquí la capacidad de analizar cada uno de estos extremos, sí queremos llamar la atención sobre que es un proyecto ambicioso de profundización del modelo económico y político en el seno de la Eurozona, con relevantes instrumentos de acción común y que se comparte con los principales Gobiernos de los Estados miembros, lo que supone una importante coalición.

\footnotetext{
${ }^{79}$ Ibid., p. 13.

${ }^{80}$ En otro lugar hemos estudiado las causas de la crisis y los efectos que ha desplegado sobre el modelo político europeo. Ver: Guinea Llorente, Mercedes, "Las consecuencias de la crisis económica para el modelo político de la Unión Europea: profundización, diferenciación y demandas de legitimidad", en: VV.AA. (2014): XXXIII Cursos de Derecho Internacional y Relaciones Internacionales de Vitoria-Gasteiz, Cizur Menor, Civitas, (en prensa).

${ }^{81}$ The Future of Europe Group of the Foreign Ministers of Austria, Belgium, Denmark, France, Italy, Germany, Luxembourg, the Netherlands, Poland, Portugal and Spain Final Report, Informe Final (17 September 2012).
} 
En relación con el ámbito concreto de la seguridad, la ESN también peca de generalista y obvia, describe la realidad actual, de forma simplista y parcial, pero sobre todo no plantea objetivos para el futuro. Afirma que "la seguridad de España se verá reforzada si la UE se consolida como un actor global" 82 . Para ello fija en tres los objetivos: el refuerzo del Servicio Europeo de Acción Exterior (SEAE), el desarrollo de una Política Común de Seguridad y Defensa y del Espacio de Libertad, Seguridad y Justicia. Esas tres líneas de acción, tan generales, es lo mismo que no decir nada, y desde luego deja en el tintero muchos otros aspectos del actor global, esenciales para la seguridad de los Estados miembros, que requieren desarrollo e implementación, entre los que se pueden citar cuestiones como la política comercial, la política energética común, prevista en Lisboa y no desarrollada, o la acción europea ante el cambio climático, por sólo citar algunas.

Y ello por no hablar del principal obstáculo para el desarrollo de una Política Exterior de la UE, como es la cuestión de su naturaleza intergubernamental, y la posibilidad de pensar en el futuro un marco político para incrementar su eficacia. En esa falta de voluntad común de los Estados miembros estriba en buena medida la debilidad actual de la UE en escenarios donde antaño tuvo protagonismo y su desplazamiento por otros actores internacionales. La cuestión fundamental es casi existencial, si los Estados miembros están dispuestos a que la UE cuente con una política exterior a la altura de sus necesidades, tendrán que ceder competencias, o al menos ampliar el número de decisiones que se puedan tomar por mayoría cualificada. Esto va en paralelo con el sentir de la opinión pública, que apoya mayoritariamente el desarrollo de una Política Exterior y una Política de Defensa en sede europea $^{83}$.

En relación a la Política Común de Seguridad y Defensa (PCSD), la ESN se extiende un poco más sobre la gestión de crisis europea, de la cual alaba la utilidad de su enfoque singular de combinar medios militares y civiles ${ }^{84}$. Se contenta con añadir que la UE debe abundar y profundizar en este ámbito como forma de contribuir a la seguridad de España y Europa. Otra vez un enfoque excesivamente simplista y generalista, que no tiene nada de estratégico y que obvia, incluso, los debates abiertos en este momento en este ámbito ${ }^{85}$. No tenemos ninguna mención a los instrumentos del Tratado de Lisboa para desarrollar una Política de Defensa Común, que refuerce la seguridad de sus Estados miembros, como son la cláusula de defensa mutua y la cláusula de solidaridad, como sí hace el Libro Blanco francés. Tampoco a la importancia de la cooperación en materia de investigación y desarrollo industrial en temas de defensa que se está desarrollando en este momento en el seno de la Agencia Europea de Defensa.

En el contexto actual de recortes económicos que afectan seriamente a las capacidades de defensa españolas, el desarrollo de la PCSD en todos sus componentes, y no sólo en la gestión de crisis, se convierte en vital para la seguridad española. Nos parece evidente que, contra lo que dispone la propia ESN, en su situación financiera, España no se halla en

\footnotetext{
82 "Estrategia de Seguridad Nacional" (2013), p. 13.

${ }^{83}$ Sobre esta cuestión del apoyo ciudadano con sus luces y sombras, véase: De France, Olivier: "What EU citizens think about European defence", European Union Institute for Security Studies Brief, n 43 (November 2013).

84 "Estrategia de Seguridad Nacional" (2013), p. 13.

${ }^{85}$ En diciembre de 2013 se celebró un Consejo Europeo monográfico sobre el desarrollo de la Política Común de Seguridad y Defensa con relevantes resultados en el ámbito de la cooperación en materia de capacidades y de proyectos comunes en innovación tecnológica e industrial. Ver: Consejo Europeo: "Conclusiones", EUCO 217/13, Bruselas (19 y 20 de diciembre de 2013).
} 
condiciones de intervenir sola ${ }^{86}$. Incluso las capacidades mínimas de defensa con las que cuenta se encuentran gravemente amenazadas por el plan de austeridad impuesto. Por ello, el desarrollo de la cooperación europea en materia de capacidades, armamento, investigación e industria en el seno de la UE se convierte en vital para que nuestro país pueda garantizar una mínima operabilidad a sus Fuerzas Armadas. Esta debería ser una prioridad máxima de la ESN, como sí ocupa un lugar destacado en las Estrategias de países como Italia y Francia.

La Estrategia no da cuenta de la realidad, en que España está cooperando de hecho con otros países europeos en iniciativas de Pooling\&Sharing desarrolladas en el seno de la $\mathrm{UE}^{87}$. Y participa también en otros relevantes proyectos, desarrollados entre Estados miembros en paralelo a la UE, que siguen la inspiración europea de la integración, siendo el más relevante, el Mando Europeo de Transporte Aéreo, conocido por sus siglas EATC ${ }^{88}$. En todos los ámbitos de Seguridad y Defensa, la cooperación intergubernamental se ha incrementado notablemente en los últimos años y sabemos que en los próximos existe un consenso importante entre relevantes Estados para darle impulso ${ }^{89}$. España debería, por tanto, clarificar sus intereses frente a esa Política Europea de Defensa Común y promover actuaciones junto con otros Estados para desarrollarla, porque nada puede ir más en su interés en su situación de vulnerabilidad actual.

El ámbito de acción Unión Europea en la ESN introduce además una breve mención a que el "contexto geopolítico" subraya la necesidad de reforzar la cooperación con Portugal y Francia ${ }^{90}$. Más que por criterios geopolíticos, parece que esta reflexión generalista y un poco peregrina se plantea sobre la base de las fronteras comunes, pero poco más. Sobre esta alusión que no se entiende, debería primar un llamamiento a la formación de coaliciones con otros Estados miembros que, en cada momento, tengan una situación objetiva similar e intereses comunes o compatibles para hacer avanzar el proyecto europeo o adoptar decisiones políticas similares en materias que incrementen la seguridad española.

Esas coaliciones existen y se adaptan a las circunstancias de cada momento y a los temas en discusión. Entre las que se han planteado hasta este momento ante el proyecto de integración futura destaca el Grupo de los doce Gobiernos sobre el Futuro de Europa, que comparten una visión, aunque sea de mínimos, común sobre el proyecto europeo. Pero, también, en decisiones concretas del Consejo Europeo o del Eurogrupo se ve cómo España ha construido con los países rescatados y amenazados por altos déficits alianzas para defender una inaplicación inmediata de sanciones o para favorecer políticas públicas de crecimiento y fomento del empleo ${ }^{91}$.

\footnotetext{
86 "Estrategia de Seguridad Nacional" (2013), p. 12.

${ }^{87}$ Podría discutirse si puede considerarse una referencia indirecta la cuarta línea de acción para desarrollar el objetivo de la defensa nacional donde se afirma "Se compartirán capacidades con nuestros aliados en el ámbito de las organizaciones internacionales de seguridad sin afectar al cumplimiento de las misiones asignadas". Entendemos que no, que aquí se está refiriendo a la OTAN (aliados) y la iniciativa que planteó en competencia denominada "Smart Defence".

${ }^{88}$ Sobre esta cuestión, ver: García Servert, Rubén Carlos: "Iniciativas "Pooling \& Sharing” en el seno de la UE. El Mando de Transporte Aéreo Europeo”, en Aldecoa Luzárraga, Francisco (ed.): "El proceso hacia unas fuerzas armadas europeas: realizaciones y desafíos", Ministerio de Defensa, Cuadernos de Seguridad y Defensa, $\mathrm{n}^{\circ} 55$ (Marzo de 2013), pp. 35-48.

${ }^{89}$ En relación a los recientes desarrollos de la cooperación en materia de defensa en la UE, ver: Missiroli, Antonio (dir.) (2014): Defence matters: EU key documents 2013, Paris, European Union Institute for Security Studies.

90 "Estrategia de Seguridad Nacional" (2013), p. 13.

${ }^{91}$ En este sentido puede recordarse la alianza Rajoy-Monti en febrero de 2012 para promover una carta, apoyada por otros diez Estados miembros, y que no contaba con el apoyo de Francia y Alemania, para solicitar de las
} 
Finalmente, ese apartado de la ESN menciona los problemas que plantea la situación de Gibraltar, tanto para las relaciones bilaterales con el Reino Unido como para la seguridad europea $^{92}$. Indudablemente es un tema que afecta a la seguridad española, y a viejas e irrenunciables demandas de soberanía, pero que afecta más a las relaciones bilaterales que a la UE propiamente dicha, dado el compromiso adquirido entre los dos Estados de resolver esta cuestión por la vía bilateral y no en el seno de la $\mathrm{UE}^{93}$. Pensamos que se trata aquí por una mera cuestión geográfica, pero no parece oportuno incluirlo bajo el epígrafe UE.

En conclusión, la UE como ámbito de acción, presenta un tratamiento del carácter estratégico que supone el desarrollo del proyecto europeo para un país como España muy deficiente. Abunda en un tono declarativo e, incluso, hasta normativo, pero no pasa de generalidades sin abordar los desafíos que cercan a la UE, ni el proyecto de UE que interesa a España en un momento en que éste se encuentra en redefinición. Lo mismo cabe decir respecto a la Política Exterior y el desarrollo de la PCSD, que siendo ambos vitales para asegurar la presencia española en la globalización, sus intereses y su seguridad, apenas se describen sin entrar a fondo en sus verdaderas implicaciones. En conclusión, se echa de menos que la estrategia no plantee un proyecto de país para la UE, que pueda implicar a todas las capacidades del Estado y defenderse coordinada y coherentemente por todos los cauces de participación que tiene España en las instituciones de la UE.

\subsection{La dimensión europea como instrumento para reforzar la defensa de los intereses españoles y su seguridad}

En tercer lugar, el último vector a analizar en la ESN supone valorar y evaluar si se integra la dimensión europea con carácter instrumental. Esto es, nos preguntamos si se ha interiorizado suficientemente la idea de pertenencia a la UE y de que se cuenta con los instrumentos de las políticas europeas, la propia estructura administrativa europea y las distintas capacidades creadas para promover y defender los intereses españoles y ganar así en seguridad. Para ello, es preciso tener en cuenta en cada uno de los elementos si el nivel europeo tiene competencias, cuáles han sido las normativas y políticas desarrolladas y pueden resultar de utilidad para incrementar y reforzar la seguridad española.

Igualmente debe pensarse en clave de futuro, y preguntarnos sobre si el enfoque y las herramientas europeas son suficientes y sobre qué otras actuaciones comunes o normativa europea sería necesaria para reforzar la seguridad española y europea. España como Estado debe integrar en su visión de las herramientas políticas disponibles el nivel europeo y promover a través de los órganos del Estado una decisión europea acorde con nuestros intereses. En ocasiones, los intereses españoles serán concurrentes con los de otros Estados miembros o, sin serlo, podrán ser asumidos por los otros socios en ese intercambio de cromos que son las negociaciones europeas. En otras, pueden chocar con otros Estados miembros, entonces habrá que explorar las mejores vías para conseguir aliar coaliciones y voluntades, incluso de otras instituciones, para sacar adelante una decisión acorde con su posición.

En la ESN es relevante la ausencia de referencias a instrumentos y capacidades institucionales europeas para promover intereses y seguridad para España. Como ya ocurre en otros campos, la ESN pasa de puntillas sobre la potencialidad que tiene el SEAE para

instituciones comunes el apoyo financiero a los Estados amenazados y el desarrollo de políticas de crecimiento y empleo que contrarrestasen la austeridad.

92 "Estrategia de Seguridad Nacional" (2013), p. 14.

93 Véase al respecto la Declaración de Bruselas, suscrita por los Gobiernos británico y español de 27 de noviembre de 1984. 
defender intereses españoles en el exterior e, incluso, permitir una presencia española en países donde los costes económicos desaconsejarían la apertura de una Embajada ${ }^{94}$. La ESN, así, no refleja la realidad de los acuerdos alcanzados entre España y el SEAE para destacar diplomáticos españoles en las Delegaciones de la UE en Estados con una especial peligrosidad o en aquellos donde el alto coste económico desincentivaría la presencia diplomática española, como ha sido el caso de Libia, Siria, Yemen o el de Sudán del Sur. Debería extenderse esta posibilidad para reforzar la presencia española en áreas donde se encuentre poco representada como una salida importante a las restricciones impuestas por la austeridad.

5.3.1. La Unión Europea como instrumento para reforzar la presencia de España en las regiones de prioridad estratégica

\section{A) El Mediterráneo}

Por proximidad geográfica, la ESN destaca sobre las demás la prioridad estratégica que supone el Mediterráneo ${ }^{95}$. En este caso, encontraremos alusiones generalistas a la promoción de la paz, la estabilidad y la prosperidad en la Orilla Sur de forma bilateral y a través de la UE al igual que a la resolución del conflicto palestino-israelî́ ${ }^{96}$. Incluso se mencionan los marcos de cooperación que la UE ha puesto en marcha con esta región (la Política Europea de Vecindad y la Unión por el Mediterráneo) al mismo nivel que otras iniciativas de otros foros internacionales ${ }^{97}$. Existe, por tanto, una mención genérica a la UE, como si se tratara de una más de las organizaciones internacionales en las que España participa, que nos parece claramente insuficiente.

Lo generalista y difuso de la redacción no refleja las implicaciones reales que el Mediterráneo tiene para España, desde su dimensión de participación en la UE, ni tampoco el hecho de que la pérdida de protagonismo de la UE en esta región amenaza directamente a nuestro país. La importancia que para los intereses españoles tenía actuar desde la UE se tenía muy claro en el pasado, teniendo en cuenta que España impulsó el establecimiento de la Asociación euro-mediterránea en la década de los noventa ${ }^{98}$. No tenemos una evaluación de los desafíos, ni de las interdependencias, ni de las mejores vías de actuación para una acción europea en el Mediterráneo. Analizar los desafíos nos va a llevar a la desestabilización política, dentro de la cual habría que plantear la ineficacia de los marcos políticos europeos desarrollados hasta el momento y la necesidad de promover en el seno de la UE, dado nuestro interés directo, un nuevo modelo de relación política que sea mejor recibido por parte de los terceros Estados y más eficaz. Es una prioridad en este terreno construir coaliciones en el seno de la UE con aquellos países con los que tenemos intereses comunes en esta región para

\footnotetext{
${ }^{94}$ Véase sobre esta cuestión: Wouters, Jan et al. (2013): The Organisation and Functioning of the European External Action Service: Achievements, Challenges and Opportunities, Luxembourg, European Parliament; Guinea Llorente, Mercedes (2014): El Servicio Europeo de Acción Exterior: los primeros dos años y medio de vida, en Rueda Fernández, Casilda (dir.): Principales manifestaciones de la Acción Exterior de la UE a la luz del Tratado de Lisboa, Cizur Menor, Thomson-Reuters Aranzadi, pp. 67-78.

95 Ya hemos mencionado como afirma que Europa y el Mediterráneo constituyen las grandes prioridades estratégicas; ver: "Estrategia de Seguridad Nacional" (2013), p. 12.

${ }^{96}$ Ibid., pp. 14-15.

97 “España debe fomentar la seguridad común en el Mediterráneo no únicamente de forma bilateral, sino también a través del impulso y liderazgo de marcos más amplios de cooperación, como la Unión por el Mediterráneo, la Política Europea de Vecindad y otros foros, como por ejemplo, la "Iniciativa 5+5”, el Diálogo Mediterráneo de la OTAN o la Iniciativa de Cooperación de Estambul de 2004: Ibid., p. 15.

${ }^{98}$ Sobre esta cuestión, véase: Blanc Altemir, Antonio (2012): La Unión Europea y el Mediterráneo. De los primeros acuerdos a la Primavera Árabe, Madrid, Tecnos.
} 
impulsar una acción decidida hacia esta región. Está claro que en una UE ampliada, el Mediterráneo no tiene tanta relevancia como lo tuvo en los años noventa, de ahí lo fundamental de construir esa masa crítica para volver a centrar la prioridad europea en la región.

En segundo lugar, la proximidad con el Mediterráneo afecta directamente a los intereses económicos españoles, que tampoco se mencionan. En las relaciones económicas con los países de la zona, sean puramente comerciales, agrícolas o pesqueras, la dimensión europea habría de tenerse en cuenta, dada la falta de competencia nacional en estos ámbitos. Para ello, hay que tener presente que la arena donde se pelean los acuerdos pesqueros con, por ejemplo Marruecos, es Bruselas y, desde allí, es preciso que el Estado español actúe para proteger los intereses españoles en una doble negociación. Primero, entre los Estados miembros de la UE para fijar una posición europea que tenga debidamente en cuenta el interés español y, luego, en las negociaciones bilaterales con el tercer Estado para defender aquellos aspectos de la posición europea que más favorables son a lo español.

En tercer lugar, tendría que tenerse en cuenta los desafíos especiales que el Mediterráneo entraña para España desde el punto de vista de la seguridad y tratar de utilizar un instrumento europeo remozado. Aunque pueden ser varios los desafíos a proponer, dada la ampliación del espacio de seguridad mediterráneo, vamos a centrarnos como ejemplo en dos: las presiones migratorias, con los otros problemas asociados de crimen organizado o terrorismo, y la dependencia energética. Las presiones migratorias en las fronteras españolas que son frontera exterior europea son un problema que crece de magnitud año a año desde que se implementó el espacio Schengen de integración de fronteras. Aun cuando la UE pone sobre España o Italia especiales cargas derivadas de velar por la integridad de la frontera exterior europea, al margen de instrumentos poco ambiciosos como Frontex poco hace por ayudarles a gestionar este problema que debería ser de los Veintiocho. Por ello, es necesario promover en el seno de la UE iniciativas específicas, empezando por la interlocución directa con los países de origen, una transferencia de recursos financieros para mejor afrontar esta presión, o la creación de una Policía Europea de Fronteras, encargada de apoyar los esfuerzos de los Estados miembros en esta dirección.

En el caso de la energía, España depende especialmente del Mediterráneo, no sólo por la gran importancia de los suministros argelinos, sino también por ser este mar una vía de comunicación relevante. Para reducir su exposición, España debería promover en la UE dos tipos de actuaciones singulares, una de ellas es la implementación de las disposiciones del Tratado de Lisboa relativas a una Política Común de Energía, especialmente a lo que se refiere a una política común de relación con los países suministradores de energía. En paralelo, convendría desarrollar en el plano europeo las Redes Transeuropeas de energía con vistas a estar mejor interconectados con el continente y minimizar así nuestra exposición. En ese sentido, llamaríamos la atención sobre el interés que presenta la iniciativa del Primer Ministro polaco Donald Tusk de crear una unión energética europea con la finalidad de minimizar los riesgos de la dependencia ${ }^{99}$.

\section{B) América Latina}

La UE está prácticamente ausente en la estrategia española hacia América Latina, que por otra parte, más que estrategia, es más bien un rosario de razones por las cuales España debe tener relaciones especiales. Sólo tenemos una pequeña mención a la misma, junto a otros foros

\footnotetext{
99 Tusk, Donald: “A united Europe can end Russia’s energy stranglehold”, Financial Times, 21 April 2014.
} 
regionales indeterminados y las Cumbres Iberoamericanas, como actores que pueden contribuir a abordar problemas como la debilidad institucional o el crimen organizado ${ }^{100}$. Indudablemente, entendemos que aquí se alude al hecho de que tradicionalmente la UE ha sido el primer donante de Ayuda Oficial al Desarrollo en América Latina, a través de programas no sólo de lucha contra la pobreza, sino también de construcción institucional, lucha contra las drogas, regionalización o desarrollo económico ${ }^{101}$. Se olvida la relevante asociación política que ha existido entre las dos regiones desde 1999, a iniciativa también de España, en el seno de las Cumbres UE-LAC, hoy UE-CELAC ${ }^{102}$.

Para la UE, América Latina ha sido también un importante socio comercial y, sobre todo, su principal socio en las iniciativas de regulación internacional para proveer de estructuras de gobernanza global ${ }^{103}$. Los valores que se comparten entre ambos lados del Atlántico fueron fundamentales a la hora de hacer prosperar marcos multilaterales como el Tribunal Penal Internacional, el Protocolo de Kyoto o los Objetivos de Desarrollo del Milenio. Esta relación se encuentra actualmente en retroceso por varias razones, desde el incremento de la presencia china, como la salida de gran parte de los Estados latinoamericanos de los fondos de cooperación europea.

España tuvo claro en los noventa que iba en interés propio promover una política europea sólida hacia América Latina, como vía para fortalecer su presencia allí, sobre todo la de tipo comercial y económico, que pasa por la competencia europea. Hoy debe tener claro que tiene el mismo interés estratégico, el desarrollo y fortalecimiento de los vínculos económicos y políticos en América Latina, y que el mejor vehículo para ello es actuar desde la UE, buscando coaliciones que restauren el interés perdido por una de las regiones más dinámicas del planeta.

\section{C) Estados Unidos y la relación transatlántica}

En el caso de la relación transatlántica y, especialmente, la relación con Estados Unidos justificada por ser "socio indispensable y prioritario para la gestión de los retos y oportunidades que presenta el mundo globalizado", no encontramos ninguna mención a la $\mathrm{UE}^{104}$. Esa consideración, a nuestro juicio, debería haberse incluido al menos por dos razones diferenciadas. En primer lugar, porque en el diálogo que se plantea sobre relación transatlántica, seguridad de América y África y retos y oportunidades de la globalización, España se encuentra en una posición asimétrica frente a Estados Unidos. En cambio, a través

\footnotetext{
100 "En algunos países de América Latina persisten problemas como la fragilidad institucional, la inseguridad jurídica, el poder de grupos criminales, el narcoterrorismo o el tráfico de personas. Se trata de complejos desafios que afectan también a España. La acción bilateral, los foros regionales, la UE y las Cumbres Iberoamericanas deben contribuir a hacer frente a estos retos", ver en: "Estrategia de Seguridad Nacional" (2013), p. 16.

101 Ver: Holland, Martin y Doidge, Mathew (2012): The development policy of the European Union, Basingstoke, Palgrave-Macmillan, pp. 134-158.

${ }^{102}$ Sobre la densidad de las relaciones UE-América Latina, que responden a un claro interés español, véase: Martín Arribas, Juan José (coord.) (2008): Las relaciones entre la Unión Europea y América Latina: ¿cooperación al desarrollo y/o asociación estratégica, Burgos, Universidad de Burgos; Stavridis, Stelios, Diamint, Rut y Gordín, Jorge (coords.) (2012): América Latina-Unión Europea-Unión Europea-América Latina: integración regional y birregionalismo, Zaragoza, Prensas de la Universidad de Zaragoza.

${ }^{103}$ Véase sobre esta cuestión: Guinea Llorente, Mercedes (2012): "Las relaciones entre Europa y América Latina a partir de nuestra entrada en la UE: un marco de relaciones en cambio", en Gil-Robles Gil-Delgado, José María (ed.), V Curso Europeo de Pozuelo "De la Constitución de Cádiz de 1812 a la Cumbre Iberoamericana de 2012”, Madrid, Centro de Excelencia Jean Monnet, pp. 113-126.

104 "Estrategia de Seguridad Nacional" (2013), p. 16.
} 
de la UE, se puede conseguir la defensa de los intereses españoles en un marco de diálogo más igualado.

En segundo lugar, una ESN que se propone como objetivo garantizar el bienestar de los españoles no puede obviar, como lo hace, el asunto fundamental que es hoy objeto de la agenda transatlántica como es la negociación del Acuerdo de Libre Comercio e Inversiones entre la UE y Estados Unidos ${ }^{105}$. La apertura de mercados y las oportunidades de negocio que abre este acuerdo son de primera importancia para un país como España y, globalmente, pretende contrarrestar los flujos de comercio que se están alejando peligrosamente hacia el Pacífico. Un tipo de negociación como ésta implica directamente a la UE como titular de la competencia comercial pero también a los Estados miembros como titulares de otras competencias compartidas como servicios, propiedad intelectual o inversiones. Por ello, debería destacarse las implicaciones en materia de seguridad amplia de esta cuestión y la necesidad de clarificar una posición española de negociación que busque la preservación de sus intereses.

\section{D) África}

España presenta su interés de establecer relación de cooperación con África y de fomentar la estabilidad y seguridad en tres zonas vitales, el Sahel, el Cuerno de África y el Golfo de Guinea con el objetivo de minimizar los riesgos procedentes de este continente que podrían afectar a su seguridad $^{106}$. En este apartado no se refiere el papel que la UE está desarrollando efectivamente, sólo indirectamente y de una forma enormemente generalista se llama a la necesidad de trabajar en esta zona con nuestros "socios y aliados".

Resulta incoherente poner a estas dos categorías en paralelo, toda vez que se está ignorando la realidad de la densa acción de la UE en África ${ }^{107}$. En este sentido, tanto la cooperación para el desarrollo como la gestión de crisis que se subrayan como estrategias claves son fundamentalmente de alcance europeo y no nacional. La UE es la potencia que, por vía del Fondo Europeo de Desarrollo y del Instrumento de Cooperación para el Desarrollo, más contribuye al desarrollo, la estabilidad y la lucha contra los riesgos en este continente. En un contexto en que la Ayuda Oficial al Desarrollo española ha sufrido un drástico recorte, hasta el punto de que el Gobierno español se propone hoy hacer "cooperación delegada", el objetivo de cooperación en África pasa por la UE ${ }^{108}$. Por ello, lo lógico sería que la ESN subrayara la necesidad de impulsar desde la UE proyectos en las regiones claves para España que luchen contra los factores susceptibles de generar riesgos directos para nuestro país.

\footnotetext{
${ }^{105}$ En junio de 2013 se comenzó la negociación con Estados Unidos sobre un Tratado de Asociación Comercial y de Inversiones (TTIP en sus siglas en inglés) que pretende crear un área de libre comercio entre los dos bloques. Ver al respecto: Akhtar, Shareyah Ilias y C. Jones, Vivian: "Proposed Transatlantic Trade and Investment Partnership (TTIP): in brief", Current Politics and Economics of Europe, vol. 24, n 1-2 (2013), pp. 107-122; Felbermayr, Gabriel J. y Larch, Mario: “Transatlantic Trade and Investment Partnership (TTIP): potentials, problems and perspectives", CESIFO Forum, vol. 14, no 2 (2013), pp. 49-60.

106 "Estrategia de Seguridad Nacional" (2013), p. 17.

107 Sobre las relaciones UE-África, ver: Helly, Damien et al. (2013): The implementation of the joint Africa Europe Strategy: rebuilding confidence and commitments, Luxembourg, European Parliament; Mangala, Jack (ed.) (2013): Africa and the European Union: A Strategic Partnership, Basingstoke, Palgrave-Macmillan.

${ }^{108}$ Así el propio Ministro de Exteriores, José Manuel García-Margallo reconocía en 2012 que los fondos para la cooperación de su Ministerio apenas alcanzaban el 20\% de la cantidad de la que disponía su predecesora en el cargo, Trinidad Jiménez. En este sentido, indicaba que la solución para seguir manteniendo la cooperación española al mismo nivel pasaba por hacer "cooperación delegada", esto es, ejecutada por agentes gubernamentales españoles pero a partir de financiación europea; "Margallo proyecta situar a cooperantes españoles en proyectos europeos", $A B C, 19$ de diciembre del 2012, en http://www.abc.es/espana/20121219/abcimargallo-cooperacion-201212191227.html.
} 
La ESN también obvia el hecho de que África hoy día es un elemento prioritario de preocupación para la seguridad europea y que, precisamente, en las zonas declaradas como prioritarias, la presencia española en misiones de seguridad ha sido mediante su participación en misiones de la UE, aunque sólo se mencione la de Malí109. La incoherencia ya es manifiesta en el caso de la Operación Atalanta en el Cuerno de África, que ni se menciona y que fue consecuencia de la iniciativa conjunta española y francesa. España impulsó esta operación con la finalidad de resolver un problema propio, el de la amenaza a los barcos pesqueros españoles presentes en la zona y encontró en el foro europeo el instrumento clave para defender sus intereses económicos en el Cuerno de África, que por sí sola no era capaz de asegurar.

\section{E) Asia}

Este continente en auge es abordado de forma vaga e inconcreta por la ESN. Apenas encontramos una mención voluntarista al hecho de que deben profundizarse las relaciones con esta región de forma tanto bilateral como "en el marco de la UE" plantean para esta región, y que desconoce los vínculos comerciales, son de incrementar la seguridad e incorporar a estas potencias a un futuro orden global que vele por la estabilidad mundial.

La consideración de la UE como instrumento para incrementar la defensa de los intereses españoles en Asia se justifica en un triple sentido ${ }^{111}$. En primer lugar, la relevancia de reforzar los marcos de cooperación comercial con los emergentes, fundamental para el bienestar de los españoles, pasa por una negociación desde la UE. En segundo lugar, los objetivos de consolidar la seguridad en la zona e insertar a estas potencias en el orden global sólo tienen visos de ser alcanzados desde la masa crítica que supone la UE en cualquier diálogo de naturaleza política. Además, en algunos de los casos implicados, incluso, se han establecido ya marcos institucionalizados de relación como son las Asociaciones Estratégicas o el Foro ASEM ${ }^{112}$. España debería considerar como utilizarlos para la promoción de sus intereses.

Finalmente, la ESN plantea la necesidad de incrementar la presencia de España en la región. Para ello, en el contexto de recortes del gasto público, y teniendo en cuenta la escasa presencia tradicional en muchos de estos países, podría considerarse la opción de utilizar las facilidades del SEAE, como ya se ha comentado, para conseguir representación oficial de los intereses españoles al menor coste posible.

\section{F) Rusia}

Rusia es el único ejemplo en que se define el interés español en la relación desde su pertenencia a la UE en un brevísimo análisis ${ }^{113}$. Así, se constata, como si hubiera salido de

\footnotetext{
${ }^{109}$ En los años 2013 y 2014 la UE está desarrollando un total de nueve operaciones de gestión de crisis en África: EUBAM Libia, EUTM Mali, EUCAP SAHEL Niger, EUFOR RCA República Centroafricana, EUCAP NESTOR en Kenia, Yibuti, Somalia y Seychelles, EUNAVFOR Atalanta en el Cuerno de África, EUTM Somalia, EUSEC Congo y EUPOL Congo.

110 "Estrategia de Seguridad Nacional" (2013), p. 18.

111 Sobre las relaciones UE-Asia, véase: Christensen, Thomas, Kirchner, Emil J. y Murray, Philomena (2013): The Palgrave handbook on EU-Asia Relations, Abingdon, Palgrave-Macmillan.

${ }^{112}$ La UE ha establecido asociaciones estratégicas con los siguientes países asiáticos: China, India, Japón y Corea del Sur.

113 "Rusia es el mayor vecino de la UE, un actor estratégico fundamental y de gran importancia en el mercado energético de Europa", ver: "Estrategia de Seguridad Nacional" (2013), p. 19.
} 
una pluma distinta, que la UE es el único elemento de referencia en la reflexión ${ }^{114}$. El interés español en Rusia se define por la pertenencia española a la UE. Esta excepción, en nuestra opinión, puede explicarse por la falta de cercanía geográfica y de intereses españoles directamente concernidos.

Desde la óptica de la UE, por otra parte, hay que criticar ese párrafo por reflejar la mayor de las indefiniciones y un "buenismo" que no tiene ninguna utilidad de cara a presentar la posición española en las negociaciones en sede europea para consensuar principios de acción ${ }^{115}$. No refleja realmente toda la complejidad de la dimensión estratégica de la relación europea con Rusia: los intereses económicos interrelacionados, la dependencia energética del Este de la UE y las diferencias irreconciliables sobre cuestiones vitales como la naturaleza de la relación mutua, los países de la vecindad y la estructura del mercado energético ${ }^{116}$.

\section{G) Organizaciones multilaterales}

Finalmente la ESN fija como ámbitos de acción para incrementar la seguridad de España una serie de organizaciones multilaterales como son la ONU, la OTAN, la OSCE y el G-20. En ninguno de ellos aparece ninguna mención a la UE, que en algunos casos podría resultar relevante, o bien para reforzar la representación de sus intereses, o bien para sustituir la voz española cuando ésta no está presente o es débil ${ }^{117}$. Así, específicamente España debería dar una importancia fundamental a la aplicación de la disposición de Lisboa que permite que la posición de la UE se oiga en el Consejo de Seguridad de la boca del Alto Representante cuando haya un consenso entre los permanentes ${ }^{118}$. Es una oportunidad para trasladar intereses españoles a este órgano cuando España no esté representada en el mismo. En paralelo debe considerarse la utilidad de contar con el apoyo de la voz de la UE en sus pretensiones en órganos como la Asamblea General de Naciones Unidas, donde ha obtenido

\footnotetext{
114 Sobre las complejas relaciones UE-Rusia, ver: Aggarwal, Vinod K. y Govela, Kristi (eds.) (2012), Responding to a Resurgent Russia: Russian Policy and Responses from the European Union and United States, New York, Springer; Allison, Roy; Light, Margot y White, Stephen (2006): Putin's Russia and the Enlarged Europe, London, Blackwell; Antonenko, Oksana (2010): Russia in 2030: A More Attractive Partner for the EU?, Washington, Brookings Institution Press; Delcour, Laure (2011): Shaping the post-Soviet space?: EU policies and approaches to region-building, Farnham, Ashgate; Gower, Jackie y Timmins, Graham (eds.) (2007): Russia and Europe in the Twenty-First Century: An Uneasy Partnership, London, Anthem Press; Haukkala, Hiski (2010): The EU-Russia Strategic Partnership: The Limits of Post-Sovereignty in International Relations, London, Routledge.

${ }^{115}$ Más que una reflexión estratégica parece un listado de buenos deseos como que Rusia debe favorecer la solución de los conflictos de larga duración en el Este de Europa, que debe consolidarse como un socio estratégico de la UE, etc. Después de la experiencia de la anexión de Crimea, antecedida por el conflicto con Georgia en 2008, parece que hay que plantear la relación con Rusia en términos más profundos.

${ }^{116}$ Sobre las relaciones de la UE con Rusia, véase: "Rusia y la UE en el vecindario común: entre la cooperación y la competencia", en: Morales, Javier (ed.) (2012): Rusia en la sociedad internacional. Perspectivas tras el regreso de Putin, Madrid, UNISCI, pp. 143-169.

${ }^{117}$ Sobre la relación y acción de la UE en otras organizaciones multilaterales, véase: Jorgensen, Knud Erik (2009): The European Union and International Organizations, Abingdon, Routledge.

${ }^{118}$ Artículo 34.2 párrafo tercero del TUE.
} 
recientemente el estatuto de observador reforzado ${ }^{119}$, o el G-20, donde España tiene el estatuto de invitado $y$, en cambio, la UE es miembro de pleno derecho ${ }^{120}$.

En la consideración de la UE como instrumento para reforzar la defensa de intereses españoles en foros multilaterales, España debería implementar una estrategia en un doble sentido. En primer lugar, desarrollar una posición activa en la negociación en sede europea para fijar la posición de la UE. En segundo lugar, debe apoyar las reformas, tanto de la propia UE como de otros organismos internacionales, que permitan una representación exterior más eficaz de la UE. El Libro Blanco francés defendía acertadamente que la razón de ser de la UE para sus Estados miembros era poder controlar su destino frente a la globalización. Compartiendo esta visión, consideramos que la acción conjunta en las organizaciones internacionales con los otros Estados miembros y la UE es la única vía para influir en la gobernanza de la globalización.

\subsubsection{La dimensión europea en las líneas de acción estratégicas}

En este apartado examinaremos, una a una, las líneas de acción que la ESN propone frente a las amenazas y riesgos identificados con la finalidad de incrementar la seguridad española. Examinaremos en cada una de ellas si se tiene suficiente en cuenta el hecho de la integración europea y si se contempla, o bien la acción europea, o bien algunos de sus instrumentos o políticas, como medios para reforzar la seguridad española.

\section{A) La defensa nacional como vía para hacer frente a los conflictos armados}

La amenaza directa que constituyen los conflictos armados en otras regiones del planeta se plantean en un sentido similar por la EES y la ESN, coinciden en un mismo sentido la prioridad europea y la nacional ${ }^{121}$. La ESN, además, plantea como objetivo que se tendrá que intervenir para hacer frente a conflictos armados tanto de modo individual para defender intereses o valores exclusivamente nacionales, como junto con nuestros aliados y socios, en el marco de la ONU, la OTAN o la UE ${ }^{122}$. Aunque no sea nuestro tema, nos parece ilusorio mantener la posibilidad de que España pueda intervenir en solitario, teniendo en cuenta el estado de sus finanzas públicas, que limitan notablemente la operatividad de sus Fuerzas Armadas, salvo en caso de que fuese necesario defender intereses vitales, asunto que exige una cuidadosa evaluación y preparación previa.

En las líneas de acción estratégicas, centradas en el desarrollo del concepto de defensa nacional, no hay ninguna referencia directa a la UE como instrumento para incrementar el potencial de la Defensa Nacional. Choca con la tesis mostrada tanto por las estrategias italiana como la francesa, que apuestan por un desarrollo de las capacidades europeas para reforzar la defensa nacional. Puede considerarse una mención implícita junto a la ONU y la OTAN, a

\footnotetext{
${ }^{119}$ En relación al estatuto de observador reforzado concedido a la UE en la Asamblea General, véase: Pérez Bernárdez, Carmela: "Respuestas al sistema diplomático ante el Servicio Europeo de Acción Exterior (SEAE): el caso de la Unión Europea ante la Asamblea General de las Naciones Unidas", Cuadernos Europeos de Deusto, n 44 (2011), pp. 111-145; López-Jacoíste Díaz, María Eugenia (2013): "Relaciones institucionales entre las Naciones Unidas y la Unión Europea: la opción por el multilateralismo y la cooperación”, en: Blanc Altemir, Antonio (dir.): Las relaciones entre las Naciones Unidas y la Unión Europea. Seguridad, cooperación y derechos humanos, Madrid, Tecnos, pp. 69-115.

${ }^{120}$ Sobre la composición, funcionamiento, decisión y funciones del G-20 puede verse el informe realizado por el Primer Ministro británico: Cameron, David Primer Ministro del Reino Unido: "Governance for Growth. Building Consensus for the Future", London, Prime Minister's Office (2011).

${ }^{121}$ Véase al respecto: "Estrategia de Seguridad Nacional" (2013), pp. 24-25.

122 Ibid., p. 40.
} 
través de la alusión al "sistema de seguridad colectiva" y a la participación en operaciones en el exterior para "contribuir a la posición internacional de España"123. Entendemos que podrían implícitamente incluirse las misiones de gestión de crisis de la UE, en muchas de las cuales participa España. En los esfuerzos de cooperación en materia de capacidades, por el contrario, sostenemos que la ESN, indirectamente, sólo considera el ámbito OTAN al hablar de "aliados" y no de "socios", de acuerdo con el lenguaje que se viene utilizando a lo largo de toda la Estrategia ${ }^{124}$.

Por todo ello, estimamos que la UE no recibe el protagonismo que debiera en relación a su contribución a la Defensa Nacional, lo que no refleja la realidad de lo que se está haciendo en el día a día ${ }^{125}$. A nuestro juicio, existen ausencias difícilmente justificables que serían claves en este ámbito. En primer lugar, en el marco de la seguridad colectiva no se alude, como ya se ha especificado más arriba, la cláusula de asistencia mutua, vital para cualquier Estado miembro de la UE, como sí lo hacen otras Estrategias de nuestro entorno ${ }^{126}$. Es fundamental tener en cuenta que el propio Consejo de la UE considera que esta cláusula, junto con la de solidaridad, asignan a la UE la función de proteger el territorio y la población de los Estados miembros ${ }^{127}$. Contribuyen, por tanto, a la defensa del conjunto de los Estados miembros de la UE, instrumento fundamental que se desconoce desde nuestro país.

En ese reto de continuar con el proceso de transformación de las Fuerzas Armadas en un contexto de escasez de recursos, es fundamental tener en cuenta los últimos desarrollos en materia de cooperación europea que busca incrementar la seguridad de los europeos en un contexto en que los recortes nacionales limitan el desarrollo de capacidades. Resulta llamativo que en la situación de España la ESN no mencione ninguno de estos desarrollos, especialmente las iniciativas de "Pooling \& Sharing" que se están desarrollando en el seno de la Agencia Europea de Defensa y los proyectos planeados a futuro, en los que España participa $^{128}$. También sería lógico aludir en el mismo sentido a proyectos multinacionales como el Mando Aéreo de Transporte Europeo (EATC), ya mencionado, en el cual se integrará España efectivamente en julio de $2014^{129}$. Respecto a este marco, debería plantearse si le interesa que se incorpore directamente a la UE por la vía de la Cooperación Estructurada Permanente y si podría extenderse a otros ámbitos donde las capacidades europeas son deficitarias.

Finalmente, en lo que atañe a la innovación tecnológica y la industria de defensa es relevante tener en cuenta el incremento destinado en el nuevo Plan de I+D europea a

\footnotetext{
${ }^{123}$ Así la Línea de Acción estratégica no 2 afirma: (el) "Mantenimiento del compromiso de España con el sistema de seguridad colectiva sobre la base de la integración en las organizaciones internacionales y mediante la activa participación en operaciones en el exterior", en: Ibid., Idem.

${ }^{124}$ Así la Línea 4 sostiene: "Se compartirán capacidades con nuestros aliados en el ámbito de las organizaciones internacionales de seguridad sin afectar al cumplimiento de las misiones asignadas”, Ibid., Idem.

${ }^{125}$ En otro trabajo hemos analizado el importante alcance de los últimos desarrollos de la Política Común de Seguridad y Defensa para la seguridad y defensa de la UE y de sus Estados miembros. Véase: Guinea Llorente, Mercedes: "La Política Común de Seguridad y Defensa (PESD):Paso inconcluso hacia las Fuerzas Armadas Europeas", en Aldecoa Luzárraga, Francisco (ed.): "El paso hacia unas Fuerzas Armas de la Unión Europea: realizaciones y desafíos", Ministerio de Defensa, Documentos de Seguridad y Defensa, no 55 (Marzo de 2013), pp. 11-28.

${ }_{126}$ Artículo 42.7 del Tratado de la Unión Europea.

127 "Memorandum of the EU's Common Security and Defence Policy against the backdrop of the entry into force of the Lisbon Treaty", General Affairs Council and Foreign Affairs Council, Bruselas (16 de junio del 2010).

${ }^{128}$ Véase sobre esta cuestión: "EDA’s Pooling and Sharing", Agencia Europea de Defensa, Factsheet, Brussels (2013).

${ }^{129}$ Sobre esta cuestión, véase el trabajo ya citado: García Servert, op. cit.
} 
investigación en este ámbito, que coordinará la Agencia Europea de Defensa, y el interés español de participar en proyectos ${ }^{130}$. En suma, consideramos que la ESN no hace un uso suficiente de los instrumentos que se han desarrollado en el seno de la UE para responder a los desafíos de la Defensa Nacional, en muchos de los cuales España se encuentra de hecho participando.

\section{B) Lucha contra el terrorismo}

La amenaza terrorista, también destacada en la EES, es un ejemplo de cómo se propone para la acción nacional el marco estratégico adoptado en el seno de la UE: la Estrategia de Lucha contra el Terrorismo adoptada en $2005^{131}$. No obstante, la ESN utiliza como referencia su estructura dividida en cuatro pilares, pero no pasa de esta referencia de un punto de vista formal $^{132}$. La ESN no tiene en consideración otros instrumentos europeos, legislativos, políticos o institucionales, para reforzar la actuación nacional. En ese sentido, desde un punto de vista instrumental, sólo se recoge la acción común en el seno de la UE para prevenir el terrorismo en terceros Estados ${ }^{133}$.

La UE cuenta con una herramienta política fundamental para luchar contra el terrorismo que se encuentra infrautilizada. Se trata de la cláusula de solidaridad del artículo 222 TFUE que dispone la obligación de asistencia de los Estados miembros y de la Unión, con medios civiles y militares, a un Estado miembro que lo requiera con el fin de prevenir la amenaza terrorista, proteger a las instituciones democráticas y a la población civil de posibles ataques terroristas y ayudarle en caso de ataque terrorista. Este artículo del Tratado prevé la necesidad de su desarrollo legislativo para acordar sus modalidades de aplicación, que todavía no se ha producido $^{134}$.

Entre los instrumentos políticos destacan por su utilidad el Plan de Acción Europeo de 2011 y la Estrategia marcada en el Programa de Estocolmo, pero también instrumentos ya existentes como la Euroorden, la cooperación entre policías nacionales europeas y autoridades judiciales para prevenir, detectar y luchar contra el terrorismo, Directivas para evitar la financiación de las redes terroristas, etc ${ }^{135}$. Existen además órganos puramente europeos para luchar contra el terrorismo como es Europol, Eurojust o el Coordinador Europeo para la Lucha Antiterrorista. Igualmente, de cara al futuro incluso podría plantearse si la Fiscalía Europea que se está creando para perseguir delitos contra el presupuesto comunitario no podría también recibir la competencia de coordinar la investigación judicial para luchar contra

\footnotetext{
${ }^{130}$ Sobre esta cuestión de la cooperación en materia de innovación tecnológica y el Pooling \& Sharing ha profundizado una reciente reunión del Consejo Europeo: Consejo Europeo: "Conclusiones", EUCO 217/13, Bruselas, 19 y 20 de diciembre de 2013.

${ }^{131}$ Consejo de la Unión Europea: "Estrategia de la Unión Europea de Lucha contra el Terrorismo", 14469/4/05, Bruselas (30 de noviembre de 2005).

${ }^{132}$ Esos cuatro pilares son la prevención, protección, persecución y preparación de la respuesta.

${ }^{133}$ Así la Línea de Acción primera establece que: "En el ámbito externo, se participará en el desarrollo de una política concertada y coordinada con los países democráticos -preferentemente mediante la acción común en el seno de la UE- y se cooperará en el combate de la radicalización en su origen". "Estrategia de Seguridad Nacional" (2013), p. 41.

134 El Parlamento Europeo lleva tiempo solicitando la aprobación de la normativa necesaria para la implementación de esta cláusula y la de asistencia mutua. Véase a título de ejemplo: Parlamento Europeo: "Resolución sobre las cláusulas de defensa mutua y de solidaridad de la UE: dimensiones política y operativa", A7-0356/2012, Estrasburgo (22 de noviembre de 2012).

${ }^{135}$ En relación a la actuación europea de lucha contra el terrorismo, véase con carácter general: Bossong, Raphael (2012): The evolution of EU counter-terrorism: European security policy after 9/11, Abingdon, Routledge; Acosta Arcarazo, Diego y Murphy, Cian C. (2014): EU Security and Justice Law: After Lisbon and Stockholm, Oxford, Hart.
} 
amenazas terroristas de carácter transnacional que afecten a más de un Estado miembro ${ }^{136}$. En definitiva, la Estrategia ampliamente ignora y no utiliza múltiples instrumentos que la UE pone a su disposición para luchar contra el terrorismo.

\section{C) Ciberseguridad}

Ni en el análisis del riesgo que suponen las ciberamenazas ni en las líneas de acción para obtener ciberseguridad existe ninguna mención específica a la UE como tal, ni a ninguna de las realizaciones de la política común ${ }^{137}$. Podríamos considerar la existencia de una alusión implícita en la sexta línea de acción, donde considera la "intensificación de la colaboración internacional" entre los países que persiguen un entorno seguro y fiable ${ }^{138}$. La UE ha desarrollado recientemente una densa actividad legislativa, institucional y de debate político, alguna de ella justo en los meses posteriores a la adopción de la ESN. Ante la imposibilidad de medidas de gobernanza global, el nivel regional es mucho más adecuado que el puramente nacional para abordar una cuestión como es el ciberespacio, que no conoce fronteras y cuya seguridad cada día es más vital para cualquier sociedad.

En el año 2013, la UE presentaba su Estrategia de Ciberseguridad, denominada "Un ciberespacio abierto, protegido y seguro", elaborada conjuntamente por la Comisión y la Alta Representante, en desarrollo de la Estrategia de Seguridad Interior de la UE ${ }^{139}$. Sus objetivos fundamentales se articulan en torno a cinco líneas fundamentales: la ciberresiliencia, la reducción de la delincuencia en la red, el desarrollo de una política de ciberdefensa en el marco de la PCSD, el desarrollo de recursos industriales y tecnológicos en materia de ciberseguridad y la promoción de una política internacional en torno al ciberespacio.

Ese mismo año entraba también en funcionamiento el Centro Europeo de Ciberdelincuencia, en la sede de Europol, y se adoptaba una Directiva sobre ataques contra los sistemas de información, que armoniza las definiciones de las infracciones penales y las sanciones en materia de ataques contra sistemas de información ${ }^{140}$. Quiere también facilitar la lucha contra la delincuencia en este ámbito y mejorar la cooperación entre las autoridades judiciales y otras autoridades nacionales. Además se presenta una propuesta de Directiva, en el momento en que escribimos todavía a la espera de la primera lectura en el Parlamento, con medidas para garantizar un elevado nivel común de seguridad de las redes y de la información en la Unión ${ }^{141}$. Esta Directiva plantea una serie de elementos entre los que destacan Centros de Seguridad de Redes en cada Estado, mecanismos de cooperación entre los Estados y la Comisión y la obligación para los operadores de infraestructuras críticas de adoptar prácticas

\footnotetext{
${ }^{136}$ European Commission: "Better protection of the Union's financial interests: Setting up the European Public Prosecutor's Office and Reforming Eurojust" Communication to the European Parliament, the Council, the European Economic and Social Committee and the Committee of the Regions, COM (2013) 532 final, Brussels (17 de julio del 2013).

${ }^{137} \mathrm{Al}$ contrario, se afirma la inexistencia de "legislación armonizada en materia de ciberseguridad", suponemos que en el seno de la UE aunque no se afirme explícitamente. "Estrategia Europea de Seguridad" (2013), p. 27.

${ }^{138}$ Ibid., p. 42.

${ }^{139}$ Comisión Europea y Alta Representante de la Unión Europea para los Asuntos Exteriores y la Política de Seguridad: "Estrategia de Seguridad de la Unión Europea: "Un ciberespacio abierto, protegido y seguro", Comunicación conjunta al Parlamento Europeo, al Consejo, al Comité Económico y Social Europeo y al Comité de las Regiones", JOIN (2013) 1 final, Bruselas, (7 de febrero de 2013).

${ }^{140}$ Directiva 2013/40/UE del Parlamento Europeo y del Consejo, de 12 de agosto de 2013, relativa a los ataques contra los sistemas de información y por la que se sustituye la Decisión marco 2005/222/JAI del Consejo. $D O L$ 218, del 14 de Agosto del 2013, p. 8.

${ }^{141}$ Comisión Europea: "Propuesta de Directiva relativa a medidas para garantizar un elevado nivel común de seguridad de las redes y de la información en la Unión", COM (2013) 48 final, Bruselas (7 de febrero de 2013).
} 
de gestión de riesgos. En paralelo, en el marco de la PCSD, se ha avanzado la cooperación en el ámbito de la ciberdefensa dentro del marco de la Agencia Europea de Defensa ${ }^{142}$.

Las líneas de acción de la ESN deben recoger e incorporar los elementos de la Estrategia europea y, sobre todo, de la Directiva aprobada, en la medida en que España no sólo está obligada, sino que está en su interés incorporar todas estas pautas de actuación. Además debería evaluarse cuidadosamente qué otras actuaciones deberían desarrollarse en interés de España en el ámbito europeo y promoverlas activamente, teniendo en cuenta el valor añadido del nivel regional.

\section{D) Lucha contra el crimen organizado}

Definido y considerado como amenaza a la seguridad nacional debido a su carácter transnacional, la ESN alude a que toda actuación en este ámbito debe fundamentarse en la colaboración y cooperación internacional ${ }^{143}$. En el análisis de esta amenaza tenemos una pequeña referencia al nivel de la UE como tal, pero sólo en relación a la situación geográfica de nuestro país en la frontera sur de la $U^{144}$. No parece una evaluación adecuada, ya que a nadie se le escapa que una de las causas fundamentales de la fuerte exposición española al crimen organizado es el espacio europeo física y económicamente integrado, en el que la libertad de circulación y la eliminación de fronteras contribuyen a su impunidad. Los criminales actúan fácilmente a través de las fronteras, lo que crea la necesidad de una actuación europea coherente y coordinada.

Al igual que en los casos anteriores la ESN desconoce y desatiende no sólo la ingente labor legislativa desarrollada en el seno de la UE y las capacidades institucionales existentes sino la oportunidad de considerar qué otras pueden ser necesarias para controlar de la mejor manera posible un problema al que está expuesto nuestro país ${ }^{145}$. Los Estados miembros mantienen la competencia sobre los aspectos operaciones de la lucha contra el crimen organizado y confían en el nivel europeo para facilitar coordinación y asistir a los Estados miembros en sus esfuerzos ${ }^{146}$.

El crimen organizado es objeto de atención de los marcos políticos europeos del Programa de Estocolmo y la Estrategia de Seguridad Interior de la UE y, más concretamente, se han desarrollado varias Estrategias de Lucha contra las Drogas ${ }^{147}$. En el plano legislativo se ha adoptado una gran variedad de normativa que va desde la armonización de determinados delitos y su sanción, hasta medidas para luchar contra el blanqueo de dinero y la financiación de la actividad criminal. En el apoyo operativo son muy relevantes distintos órganos europeos como las Agencias Europol, Eurojust, CEPOL y el Sistema de Información, que tienen como objetivo la coordinación de la actuación represiva nacional. Como se ha visto, el marco

\footnotetext{
142 Sobre esta cuestión, véase: Robinson, Neil: "EU cyber-defense: a work in progress", European Union Institute for Security Studies Brief, $\mathrm{n}^{\circ} 10$ (Marzo 2014).

143 "Estrategia de Seguridad Nacional" (2013), p. 43.

${ }^{144}$ Ibid., p. 28.

${ }^{145}$ Véase entre otros trabajos recientes: Acosta Arcarazo y Murphy, op. cit.

146 Así, por ejemplo, la oficina de coordinación policial "Europol" aprueba con carácter periódico el SOCTA (Serious Organized Crime Threat Assessment), documento de análisis de la amenaza de la criminalidad organizada a escala europea con el objetivo de servir de marco estratégico de referencia a las autoridades nacionales y europeas y fijar objetivos comunes. Ver: Europol: "Serious Organized Crime Threat Assessment 2013", European Police Office, La Haya (2013).

147 Para una evaluación del desarrollo del Espacio de Libertad, Seguridad y Justicia a través de la implementación del Programa de Estocolmo, véase: Labayle, Henri (2013): Vers la négociation et l'adoption du programme succedant à Stockholm pour la période 2015-2019, Bruxelles, Parlement Européen.
} 
europeo contiene una variedad relevante de instrumentos y realizaciones para apoyar la lucha de los Estados miembros contra el crimen organizado de carácter transnacional, que no se integran en un documento que tiene la vocación de incorporar todos los instrumentos con los que cuenta el Estado.

\section{E) Seguridad económica y financiera}

Si existe un ámbito donde la autonomía de un Estado miembro de la Eurozona ha desaparecido, es precisamente en materia de seguridad económica y financiera, por la considerable cesión de soberanía que supone la moneda única ${ }^{148}$. Como consecuencia de la crisis económica y financiera, se ha producido en los años 2011 a 2013 una profundización de la integración económica sin precedentes, a partir de reformas de los Tratados, Tratados nuevos o, incluso, legislación secundaria ${ }^{149}$. Esa profundización trata de completar la Unión Monetaria existente con una Unión Económica que no se pactó en Maastricht y ha conducido de hecho a la supervisión europea de las políticas macroeconómicas, financieras y presupuestarias de los Estados del Euro, limitando muy considerablemente una autonomía que ya era pequeña. Por ello, parece completamente ridículo que la ESN plantee como riesgo relevante la inestabilidad económica y financiera sin hacer una sola mención al hecho de la integración española en la Unión Económica y Monetaria, con el agravante de que actualmente este es el único marco en que se puede abordar esta cuestión ${ }^{150}$.

De las ocho líneas de acción planteadas bajo el objetivo de la seguridad económica y financiera, sólo una se dedica específicamente a la acción en el seno de la UEM, y propone el desarrollo de este marco para construir una gobernanza económica y financiera efectiva de la UE. En las siete líneas restantes se supone que el Estado podría actuar en solitario, lo que es muy discutible, ya que en la mayoría de los casos se necesitará actuar en el sentido marcado desde las instituciones comunes. Es el caso de la primera línea donde se propone la potenciación de un modelo económico sostenible, se depende de la política monetaria del BCE, así como de las directrices comunes de coordinación económica, propuestas por la Comisión y adoptadas por el Eurogrupo. Lo mismo cabe decir de las líneas de acción relativas al marco socio-laboral, determinado por la coordinación del Semestre Europeo. La promoción de una economía internacional abierta y el establecimiento de mecanismos de regulación y supervisión a escala internacional sólo parecen posibles si se hace desde la UE y como miembro de la misma, dado el escaso peso real de España en los foros económicos internacionales.

En el punto dedicado a la UE el objetivo que se plantea es la revisión del marco de gobernanza europea, desde un punto vista constitucional. El objetivo es "una gobernanza económica y financiera efectiva de la UE, que asegure la sostenibilidad y el buen funcionamiento de la UEM y la fortaleza del euro. Se cooperará activamente en la construcción de un gobierno económico europeo con instrumentos comunes y políticas económicas coordinadas que incluirán igualmente el estudio de medidas de vigilancia de los

\footnotetext{
${ }^{148}$ Sobre las características y el funcionamiento de la Unión Económica y Monetaria, véase: Chang, Michele (2009): Monetary Integration in the European Union, Basingstoke, Palgrave-Macmillan; Geeroms, Hans; Ide, Stefaan y Naert, Frank (2014): The European Union and the Euro: how to deal with a currency built on dreams, Cambridge, Intersentia.

${ }^{149}$ En otro lugar hemos analizado, entre otros efectos políticos, la relevante profundización producida durante la crisis del euro, que ha supuesto la mutación de la Constitución económica de la UE. Ver: "Las consecuencias de la crisis económica para el modelo político de la Unión Europea: profundización, diferenciación y demandas de legitimidad", en: VV.AA., XXXIII Cursos de Derecho Internacional y Relaciones Internacionales de VitoriaGasteiz, Vitoria-Gasteiz, Aranzadi (en prensa).

${ }^{150}$ Véase para la evaluación de este riesgo: "Estrategia de Seguridad Nacional" (2013), pp. 28 y 29.
} 
paraísos fiscales" ${ }^{\prime 151}$. Esta mención relativa a la profundización de la eurozona no puede ser calificada sino de demasiado generalista, que peca de indefinición, y en muchos casos, se encuentra desfasada.

No da cuenta de mucho de lo que ya se ha conseguido a través de la profundización de estos últimos años en materia de gobernanza económica y financiera que va desde las facultades de supervisión que han recibido las instituciones comunes sobre presupuestos nacionales y políticas económicas de los Estados de la Eurozona y la capacidad de definir un marco de coordinación común ${ }^{152}$.Tampoco especifica cuáles son los verdaderos temas de interés nacional para España en ese momento de cara al futuro de la profundización de la Eurozona, como la Unión Bancaria - que se acaba de culminar-, las posibilidades de mutualización de la deuda soberana, instrumentos comunes de apoyo para las reformas estructurales nacionales o la inaplazable dimensión social de la eurozona. Incluso la mención relativa a la vigilancia sobre los paraísos fiscales no refleja los avances en materia de cooperación alcanzados tanto en el ámbito del G-20, la OCDE y la propia UE.

Teniendo en cuenta que esta ESN se aprueba en el momento en que la UE estaba diseñando la hoja de ruta para la profundización de la Eurozona, el Informe Van Rompuy, hubiera sido lógico que se planteara el interés nacional español en relación a cada uno de los asuntos allí mencionados ${ }^{153}$. También se echa en falta que no exista una posición expresa del interés nacional frente al gran desafío que tiene hoy ante sí la UE, prever las capacidades políticas necesarias para gestionar adecuadamente la moneda común. Esto es, una gran reforma mediante una Convención que articule aquello a lo que se alude ambiguamente con la expresión de "más Europa" o en palabras de la propia ESN un "gobierno económico europeo con instrumentos comunes y políticas económicas coordinadas". Aunque fuera en términos amplios y ambiguos la estrategias francesa e italiana sí plantean una posición de partida respecto a la profundización de la integración económica. Igualmente, el Gobierno español es parte de iniciativas que apoyan la federalización de la Eurozona, que como ya se ha dicho, no encuentran reflejo en esta ESN ${ }^{154}$.

\footnotetext{
151 Ibid., p. 44.

${ }^{152}$ En este aspecto, la normativa más relevante son los paquetes legislativos conocidos como el "Six-Pack" y el "Two-Pack"; Ver respectivamente: Reglamento (UE) n. ${ }^{\circ}$ 1173/2011, sobre la ejecución efectiva de la supervisión presupuestaria en la zona del euro, DO L 306, de 23.11.2011, p. 1; Reglamento (UE) n. ${ }^{\circ}$ 1174/2011, relativo a las medidas de ejecución destinadas a corregir los desequilibrios macroeconómicos excesivos en la zona del euro, DO L 306, de 23.11.2011, p. 8; Reglamento (UE) n. ${ }^{\circ} 1175 / 2011$, por el que se modifica el Reglamento (CE) n. ${ }^{\circ}$ 1466/97 del Consejo, relativo al refuerzo de la supervisión de las situaciones presupuestarias y a la supervisión y coordinación de las políticas económicas, DO L 306, de 23.11.2011, p. 12; Reglamento (UE) n. ${ }^{\circ} 1176 / 2011$, relativo a la prevención y corrección de los desequilibrios macroeconómicos, DO L 306, de 23.11.2011, p. 25; Reglamento (UE) n. ${ }^{\circ} 1177 / 2011$, por el que se modifica el Reglamento (CE) n. ${ }^{\circ}$ 1467/97, relativo a la aceleración y clarificación del procedimiento de déficit excesivo, DO L 306, de 23.11.2011, p. 33; Directiva 2011/85/UE, sobre los requisitos aplicables a los marcos presupuestarios de los Estados miembros, DO L 306, de 23.11.2011, p. 41. Reglamento (UE) no . 472/2013 del Parlamento Europeo y del Consejo, de 21 de mayo de 2013, sobre el reforzamiento de la supervisión económica y presupuestaria de los Estados miembros de la zona del euro cuya estabilidad financiera experimenta o corre el riesgo de experimentar graves dificultades, DO L 140, de 27.05.2013, p. 1; Reglamento (UE) no. 473/2013 del Parlamento Europeo y del Consejo, de 21 de mayo de 2013, sobre disposiciones comunes para el seguimiento y la evaluación de los proyectos de planes presupuestarios y para la corrección del déficit excesivo de los Estados miembros de la zona del euro, DO L 140, de 27.05.2013, p. 11.

${ }^{153}$ Véase: Van Rompuy, Herman, President of the European Council (in collaboration with Jose Manuel Barroso, President of the European Commission, Jean-Claude Juncker, President of the Eurogroup and Mario Draghi, President of the European Central Bank), "Towards a Genuine Economic and Monetary Union", Brussels (5 December 2012).

154 "Future of the Europe Group...", op. cit.
} 


\section{F) Seguridad energética}

En el marco de este objetivo, la ESN hace mención expresa a la necesidad de poner en marcha una política energética común que fomente las interconexiones entre Estados miembros y a un mercado interior de electricidad y gas natural plenamente integrados, con el objetivo de reducir la vulnerabilidad física de los Estados europeos ${ }^{155}$. Es uno de los pocos puntos en los cuales vemos que se plantean la promoción de actuaciones europeas, para defender la seguridad nacional. La visión que se aplica, por tanto, es la de promover una futura política común como instrumento para reforzar la seguridad energética española. La ESN promueve, sin embargo, una política que tiene solamente una dimensión interior, no aborda una posición exterior común que pueda reducir la vulnerabilidad española y de los otros Estados miembros a través de una voz única.

Dado que consideramos que una política energética común en materia de abastecimientos es imprescindible, consideramos que el enfoque de la ESN no es suficiente. Se echa en falta las referencias a la dependencia energética del exterior que tiene España, al igual que el conjunto de la UE, y las capacidades que una política exterior común de aprovisionamientos induciría, reduciendo la dependencia a través del fortalecimiento de la posición común. Tal política está prevista por el Tratado de Lisboa, pero aún no ha sido implementada, continuándose con la práctica de políticas exteriores energéticas de alcance nacional ${ }^{156}$. A nuestro juicio, dado el lugar estratégico de España y su dependencia de algunos socios concretos como Argelia, está en su interés promover el desarrollo de una política exterior común de negociación de los aprovisionamientos energéticos, compatible con el fomento de la interconexión, que refuerce la seguridad energética de todos y cada uno de sus Estados miembros.

La reciente crisis de Ucrania y la posibilidad de que las relaciones europeas con Rusia se tensen han abocado, como ya se ha comentado, a que el Primer Ministro polaco plantee una propuesta de desarrollo de una Unión Energética ${ }^{157}$. En paralelo se está debatiendo la aceleración de los planes de interconexión de redes energéticas europeas. Esta propuesta se encuentra, en la actualidad, en discusión entre los Estados miembros que, ante la amenaza rusa podrían considerar la aprobación de una genuina política exterior de aprovisionamientos energéticos. Se trata de una cuestión de importantes repercusiones para un país como España que debe estudiar cuidadosamente los intereses a defender en las negociaciones.

\section{G) No proliferación de armas de destrucción masiva}

La evaluación de la amenaza de las armas de destrucción masiva es uno de los escasos ámbitos que se plantea desde la acción común desarrollada en el seno de la UE. Se utilizan así como elementos de referencia en el análisis tanto la Estrategia de la UE contra la Proliferación de Armas de Destrucción Masiva como las Nuevas Líneas de actuación aprobadas en $2008^{158}$. En el capítulo relativo a las líneas de acción estratégica, igualmente la ESN contiene una mención expresa a la cooperación con los "socios" y aliados en la lucha contra la proliferación, desde la prevención, disuasión, detención y eliminación de los programas de proliferación ${ }^{159}$. Se trata de una alusión indirecta a la UE, pues se llama a cooperar con los

\footnotetext{
155 "Estrategia de Seguridad Nacional" (2013), p. 45.

${ }^{156}$ Véase al respecto el artículo 194 del TFUE.

157 Tusk, op. cit.

158 "Estrategia de Seguridad Nacional" (2013), pp. 30-31.

${ }^{159}$ En concreto la ESN recoge en la primera línea estratégica relacionada con este objetivo "Multilateralismo eficaz y coordinación activa en la lucha contra la proliferación de las armas de destrucción masiva. La estrecha
} 
Estados miembros de la UE exclusivamente. La ESN, en cambio, no tiene en cuenta las actuaciones en materia de no proliferación que se han desarrollado en el pasado y se están desarrollando por las propias capacidades institucionales de la UE. A este respecto, es fundamental tener en cuenta el peso específico de esta organización internacional en la negociación bilateral para poner bajo control los programas que suponen amenazas a escala internacional. Tampoco menciona las dificultades que crean las políticas nucleares de Francia y el Reino Unido.

En este sentido, la ESN da cumplida cuenta de que la UE, por sí misma, es un actor relevante de los regímenes multilaterales de control de armamentos de destrucción masiva internacional así como un líder en la asistencia técnica y financiera para luchar contra la no proliferación ${ }^{160}$. Así, la UE dispone de una Estrategia en materia de no proliferación desde 2003, que ha sido revisada posteriormente y completada con otro tipo de actuaciones ${ }^{161}$. Sin embargo, no tiene en cuenta otros elementos institucionales, como el relevante desarrollo de capacidades orgánicas en el SEAE relativas a la no proliferación, para asistir a los Estados en el cumplimiento de sus obligaciones.

Esta Estrategia política viene sirviendo de referencia en las negociaciones que la Alta Representante de la UE junto con los Ministros de Alemania, Francia y Reino Unido están desarrollando con Irán para someter a control internacional su programa de desarrollo nuclear. En este sentido, se atribuye a la diplomacia europea y, especialmente a Catherine Ashton, el éxito en la negociación con Irán del otoño de 2013, que aunque todavía solo puede ser calificado de parcial y provisional, ha supuesto el desbloqueo de casi diez años de parálisis y un avance relevante para la seguridad internacional ${ }^{162}$. Además de las capacidades diplomáticas, también es relevante señalar los programas de cooperación comunes existentes para financiar esta lucha contra la no proliferación, como es el caso de la línea de financiación para el control de las tecnologías de doble uso introducida en el reformado Instrumento de Seguridad Nuclear ${ }^{163}$. En este capítulo, aun cuando la ESN utiliza el marco europeo de referencia, no plantea la multitud de instrumentos existentes para luchar contra la no proliferación.

\section{H) Ordenación de flujos migratorios}

En este capítulo, la primera constatación es que se hace una mención desigual al hecho de que las fronteras españolas son fronteras exteriores de la UE. Desde este punto de vista, resulta irregular la referencia a la problemática de la migración como consecuencia de la pertenencia de España a la UE. Así en el capítulo 3, relativo a los riesgos y amenazas a la seguridad

cooperación con los Estados miembros de la UE y los aliados OTAN - así como con otros países relevantes asociados- es fundamental para el éxito mundial de la lucha contra la proliferación y, particularmente, para la prevención, disuasión, detención y, cuando sea posible, la eliminación de los programas de proliferación de especial preocupación a nivel mundial, al igual que para prevenir el acceso por parte de grupos terroristas y otros agentes no estatales a los materiales y fuentes radioactivas", en "Estrategia de Seguridad Nacional" (2013), p. 46.

${ }^{160}$ Véase en relación a esta cuestión: Cottey, Andrew: "The EU's non-proliferation strategy ten years on", European Foreign Affairs Review, vol. 19, no 1 (2014), pp. 45-63; Kienzle, Benjamin: “A European contribution to non-proliferation?: the EU WMD Strategy at ten", International Relations, vol. 89, no 5, (2013), pp. 11431159.

${ }^{161}$ Consejo de la Unión Europea: "Estrategia de la Unión Europea contra la proliferación de armas de destrucción masiva", 15708/03, Bruselas (10 de diciembre del 2003),.

${ }^{162}$ Spiegel, Peter: "EU foreign policy chief Lady Ashton comes of age in Iran talks", Financial Times, 26 November 2013.

${ }^{163}$ Reglamento 237/2014 del Consejo, de 13 de diciembre de 2013, por el que se establece un Instrumento de Cooperación en materia de Seguridad Nuclear, DO L 77, de 15.3.2014, p. 109. 
nacional, se analiza la amenaza de los flujos migratorios irregulares como común a los de los otros Estados de la UE, cuyos desafíos y efectos desestabilizadores afectan a todos por igual $^{164}$.

Sorprende, sin embargo, que no se expliquen las razones de la presión migratoria en las fronteras españolas como derivadas de la condición de España como frontera sur de la UE y, más en concreto, como la responsable de la vigilancia de la frontera con mayor desigualdad en el planeta. Indudablemente la preocupante presión de la inmigración ilegal en las fronteras españolas se debe al hecho de la inexistencia de fronteras en el seno de la UE. Esta falta de referencia impide que se plantee posteriormente como línea de actuación demandar una mayor implicación de la propia UE y del resto de los Estados miembros en la solución de un problema común, como es que España custodie una de las fronteras comunes de la UE, atenuando en buena medida las presiones migratorias que reciben otros Estados, con las consecuencias derivadas en su seguridad.

En el mismo sentido, en el capítulo 4, relativo a las líneas de acción, la referencia a la UE y sus capacidades como instrumento es verdaderamente marginal. Se plantea como línea de acción estratégica la vigilancia y el control de las fronteras en el marco del Sistema Integrado de Fronteras Exteriores de la $\mathrm{UE}^{165}$. Este concepto alude a un conjunto de normas, organismos y procedimientos de apoyo a los Estados miembros de la zona Schengen para que puedan gestionar sus fronteras de forma coordinada. Aunque existen elementos comunes en la aproximación a la política migratoria, se trata de un ámbito donde el enfoque intergubernamental supera aún con mucho al comunitario ${ }^{166}$. Existe el consenso entre el Parlamento Europeo y la doctrina sobre las limitaciones de este sistema que no basta para asegurar la gestión solidaria común de las crisis humanitarias que están asolando la frontera Sur de la UE ${ }^{167}$.

Por ello, consideramos que resulta fundamental para incrementar la seguridad española que el Gobierno y otros representantes actúen ante las instancias institucionales europeas para promover una auténtica política común de gestión de fronteras, dado que el actual marco es claramente insuficiente. Para ello es necesario seguir dos líneas complementarias, de política interna y de política exterior. En primer lugar, en una posición maximalista debería considerarse el lobbying a favor de desarrollar una política europea de fronteras. En un enfoque más modesto, debe plantearse reforzar las capacidades comunes, incrementando, por ejemplo, la provisión del Fondo Europeo para las Fronteras Exteriores, con la finalidad de apoyar las capacidades de los Estados miembros del Sur, que no sólo son los que tienen que hacer frente a una presión migratoria mayor, sino que además están resultando más golpeados por la crisis económica. En tercer lugar, es preciso considerar dotar de más capacidades y misiones más estables para FRONTEX, de forma que se constituya en un instrumento estable de apoyo para los Estados miembros con mayores problemas. Igualmente sería relevante poner en marcha discusiones en torno al establecimiento de una policía común de fronteras.

\footnotetext{
${ }^{164}$ Se afirma así: "La Unión Europea sigue siendo un destino atractivo y un lugar de acogida para personas llegadas de las más diversas procedencias. El fenómeno de la inmigración internacional incluye la llegada, tanto a España como a Europa en su conjunto, de inmigrantes regulares e irregulares", ver en: "Estrategia de Seguridad Nacional" (2013), p. 32.

${ }^{165}$ Es la Línea de Acción 1, ver: Ibid., p. 47.

${ }^{166}$ En relación a esta materia puede consultarse la siguiente obra: Balleix, Corinne (2013): La politique migratoire de l'Union européenne, Paris, Documentation Française.

${ }^{167}$ En este sentido, el Parlamento Europeo reclamaba «la adopción de un programa exhaustivo que establezca los objetivos globales y la estructura de la estrategia integrada de la Unión en materia de gestión de fronteras, con objeto de poner realmente en práctica una política común de asilo, inmigración y control de las fronteras exteriores». "Resolución sobre el Programa de Estocolmo", Parlamento Europeo (25 de noviembre de 2009).
} 
Desde el punto de vista de la política exterior, España necesita de las capacidades de la UE para obtener los acuerdos necesarios de cooperación con los países de origen y tránsito de los flujos migratorios. Esta última cuenta con más resortes, derivados de su fortaleza como socio comercial y de potencia de la cooperación para el desarrollo para plantear contraprestaciones a la firma de estos acuerdos. Igualmente, dado su carácter transnacional, resulta evidente el mayor potencial que cuenta la UE para abordar la lucha contra las redes de delincuencia y el tráfico de seres humanos, tanto desde la colaboración entre Estados miembros como a través del desarrollo de capacidades a escala europea en una política, la lucha contra la delincuencia, que también se encuentra infradesarrollada.

En interés de la seguridad española, debe defenderse la puesta en marcha de una política migratoria común digna de ese nombre, que supere el actual protagonismo de la cooperación intergubernamental para profundizar en una dimensión comunitaria. Para ello España debería formar una coalición para tratar de defender esta postura con los Estados que sufren una presión similar, derivada de su frontera directa con Estados terceros de la UE.

\section{I) Contrainteligencia}

En materia de espionaje y contrainteligencia, la ESN no hace una alusión directa a la UE sino a la cooperación internacional con el objetivo de proporcionar una respuesta integral ${ }^{168}$. Como excepción al resto de los casos, se trata de una referencia suficiente, dado que no consideramos que la cooperación europea sea el instrumento adecuado para incrementar la seguridad a este respecto. En la medida de la importancia creciente del espionaje industrial y de la desconfianza percibida entre unos Estados miembros y otros, dudamos de la posibilidad de acción europea en este campo.

Por otra parte, tampoco nos consta la existencia de actuaciones europeas en esta materia con carácter general, que le den contenido de política estable. No obstante, la UE y los Estados miembros sí han desarrollado una coordinación y actuaciones conjuntas con carácter puntual en este ámbito en relación a asegurar el éxito de misiones comunes, como se ha dado en el caso de operaciones de gestión de crisis. Igualmente existe cooperación estable entre servicios de inteligencia en el seno de la UE con el objetivo de combatir amenazas comunes como es el terrorismo. Parece, sin embargo, difícil poder superar el nivel de la cooperación común en relación a áreas de interés común. Tenemos, por tanto, nuestras reservas sobre si se puede desarrollar una política común en este sentido por los intereses divergentes y las suspicacias existentes entre los propios Estados miembros.

\section{J) Protección ante emergencias y catástrofes}

En el ámbito de las respuestas para la protección contra emergencias y catástrofes de origen natural y humano, encontramos diversas alusiones al marco jurídico político de la UE en las distintas líneas de acción especificadas ${ }^{169}$. Se refleja así con toda lógica una línea de acción común en materia de protección civil que no ha resultado constitucionalizada hasta recientemente, con el Tratado de Lisboa ${ }^{170}$. Concebida como una competencia complementaria, de coordinación o apoyo ${ }^{171}$, el nuevo artículo 196 del TFUE recoge que los

\footnotetext{
168 "Estrategia de Seguridad Nacional" (2013), pp. 33-34 y p. 48.

${ }^{169}$ Ibid., p. 49.

170 Sobre la regulación de una nueva base jurídica en materia de protección civil, véase: Guinea Llorente, Mercedes (2011): La Convención Europea: la génesis del Tratado de Lisboa, Madrid, Congreso de los Diputados, pp. 639-645.

${ }^{171}$ Véase al respecto el artículo 6 del TFUE.
} 
objetivos de la política europea son complementar la acción de los Estados miembros en la prevención de riesgos, la formación de personas y la intervención en catástrofes y fomentar una coordinación rápida y eficaz entre los servicios nacionales tanto en intervenciones dentro de la UE como en actuaciones a escala internacional.

La ESN, en sus líneas de acción, presenta diversas alusiones a la acción común en el seno de la UE. Así en primer lugar, afirma con carácter general que se contribuirá a una mayor cooperación europea e internacional, buscando potenciar la participación en redes, planes y mecanismos europeos de preparación y respuesta. En relación a emergencias relativas al área de la salud pública, se afirma la adopción de planes de prevención y respuesta a pandemias en coordinación con el Centro Europeo para la Prevención y el Control de las Enfermedades de la UE. Igualmente encontramos una mención al papel de la Red de Seguridad Alimentaria de la UE en el caso de crisis alimentarias, fuertemente desarrollado desde los noventa como consecuencia de la crisis de las "vacas locas".

A pesar de que existe una mayor presencia de los instrumentos y políticas de la UE en este campo, sorprenden las relevantes omisiones. La primera de ellas es de rango constitucional, la cláusula de solidaridad del artículo 222 TFUE, que se activa no sólo en caso de ataque terrorista, sino también de catástrofes naturales o de origen humano y que requiere la asistencia de la UE y de sus Estados miembros con medios civiles y militares ${ }^{172}$. También sorprende que no se haga ninguna mención al Mecanismo Europeo de Protección Civil, que se activa para emergencias europeas y en terceros Estados y que ya ha cumplido una década de existencia, con un considerable valor añadido ${ }^{173}$. Existen otros procedimientos relevantes para la prevención de catástrofes a los que no se alude, como el Mecanismo de Alerta Temprana y diferentes órganos y procedimientos frente a catástrofes medioambientales, que también se echan en falta. En este punto aún cuando existen referencias al nivel de cooperación europea, éstas a nuestro juicio resultan insuficientes.

\section{K) Seguridad marítima}

El objetivo de una acción estratégica en materia de seguridad marítima se define en términos verdaderamente amplios que van desde mantener la libertad de navegación y proteger el tráfico marítimo hasta luchar contra las actividades delictivas, proteger los recursos marinos, el medio ambiente o responder a catástrofes o accidentes ${ }^{174}$. Una acción política que se define en términos tan amplios y ambiciosos no encuentra después un paralelismo equivalente en las líneas de acción estratégicas planteadas para desarrollarlo. La alusión a la UE en este ámbito es marginal e insuficiente y, si se nos permite, hasta ridícula.

Encontramos una referencia vaga a la UE en el marco de la cooperación internacional, junto con la Organización Marítima Internacional y la búsqueda de acuerdos bilaterales con países ${ }^{175}$. No se afirma a este respecto ni en qué campos se buscará esta cooperación ni con qué finalidad. Sólo se alude a que "se continuará con el proceso de implementación de la

\footnotetext{
172 Sobre la aplicación de esta cláusula al ámbito de la protección civil, véase: Kostanidines, Theodore: "Civil protection cooperation in EU law: is there room for solidarity to wriggle past?”, European Law Journal, vol. 19, $\mathrm{n}^{\mathbf{0}} 2$ (2013), pp. 267-282.

${ }^{173}$ Para una descripción de este mecanismo, puede verse: European Commission: "European Union civil protection: at a glance", Luxemburgo (2013).

174 "Estrategia de Seguridad Nacional", (2013), p. 50.

${ }^{175}$ La Línea de Acción no 3, relativa al fomento de la cooperación internacional establece: "Se continuará con el proceso de implementación de la normativa de la UE y la Organización Marítima Internacional (OMI), donde se enmarcan las actuaciones de España", en "Estrategia de Seguridad Nacional" (2013), p. 50.
} 
normativa de la UE", entendemos que refiriéndose a la seguridad del transporte marítimo y la lucha contra la piratería.

Consideramos la referencia a la UE en estos ámbitos como manifiestamente insuficiente, dado que el objetivo citado abarca ámbitos de competencia europea que no se tienen en cuenta como la política pesquera común, la energética o la de medioambiente, los transportes o la protección civil. Sorprende, desde luego, la cuestión de la gestión de los recursos del medio marino, teniendo en cuenta que dentro de ellos están los pesqueros, competencia exclusiva de la $\mathrm{UE}^{176}$.

También resulta llamativa la nula referencia a la gestión de crisis desarrollada en el marco de la Política Común de Seguridad y Defensa para garantizar la seguridad marítima, como es el caso de la Operación Atalanta, desarrollada por la UE en el Cuerno de África, a petición, entre otros, de España. Nuestro país consiguió satisfactoriamente el lanzamiento de esta operación para la defensa de sus intereses económicos en la zona, especialmente de carácter pesquero $^{177}$. Como ya se ha dicho, estamos ante un ejemplo práctico y claro de la utilización de los recursos políticos de la UE para la defensa de intereses nacionales e incremento de nuestra seguridad que la formulación de la ESN ignora.

Igualmente consideramos que existen relevantes áreas relativas a la seguridad marítima de interés para España que deberían haberse tenido en cuenta en relación a la acción UE. Así pueden citarse el desafío de la seguridad marítima en el ámbito de la migración irregular en la zona del Estrecho que tanto afecta a España y, que en ocasiones, dada la precariedad de los medios y la presión de las mafias arroja espeluznantes tragedias humanas. En este sentido, en el pasado ya se ha recurrido a más de cincuenta misiones conjuntas coordinadas por Frontex para patrullar el Mediterráneo y el Atlántico Oriental, con la finalidad de evitar los tráficos ilícitos de pateras y cayucos y tragedias humanitarias ${ }^{178}$. Teniendo en cuenta que España es uno de los Estados más beneficiados por esta cooperación europea cuyo objetivo es "proteger la vida humana en el mar" y prevenir actividades criminales, se echa en falta el recurso a estos mecanismos en las líneas de acción común. Finalmente, consideramos que existen varios instrumentos y organismos europeos que pueden permitirnos adoptar un enfoque que necesariamente ha de ser más proactivo en el caso de que existan fuertes intereses nacionales en relación a la seguridad marítima, como por ejemplo sería la situación de la seguridad del Estrecho de Gibraltar.

\section{L) Protección de infraestructuras críticas}

La ESN considera como última de las amenazas relevantes para la seguridad nacional la vulnerabilidad de las infraestructuras críticas y servicios esenciales, cuyo funcionamiento es indispensable para la seguridad, bienestar y salud de los ciudadanos y la garantía de las funciones sociales básicas y el funcionamiento de las instituciones ${ }^{179}$. En las líneas estratégicas de acción se alude a la cooperación internacional como una de las claves fundamentales y dentro de ella existe amplia referencia a los marcos europeos de actuación

\footnotetext{
${ }^{176}$ Véase al respecto el artículo 3.1 d) del TFUE.

${ }^{177}$ Sobre el impulso de España, junto con Francia, para el lanzamiento de la operación Atalanta, véase: Frutos Ruiz, Ignacio: "La lucha internacional contra la piratería marítima: Somalia y la Operación Atalanta", Instituto Español de Estudios Estratégicos (IEEE), Documento de Opinión, 16/2010 (Octubre de 2010); Guinea Llorente: "España en la Política Exterior Común europea: los últimos diez años (2001-2011)", UNISCI Discusión Papers, $\mathrm{n}^{\circ} 27$ (Octubre 2011).

${ }^{178}$ En relación a esta cuestión puede verse: European Union Agency for Fundamental Rights: "EU Solidarity and Frontex: Fundamental Rights Challenges", Luxemburgo (2013).

179 "Estrategia de Seguridad Nacional" (2013), p. 37.
} 
como son el Programa Europeo de Protección de Infraestructuras Críticas y la Directiva sobre Identificación y Designación de Infraestructuras Críticas Europeas y Evaluación de la Necesidad de Mejorar su Protección ${ }^{180}$. Ambos instrumentos son ejemplo de cooperación en el seno de la UE como forma de proteger intereses nacionales.

Igualmente se considera relevante en la ESN promover redes europeas de información, alerta temprana y respuesta, con la finalidad de proteger las infraestructuras críticas. Aún cuando no se mencione expresamente, entendemos que se alude a la ya existente y eficaz Red Europea de Información. Este es uno de los pocos casos en los cuales, siendo benévolos, puede considerarse que la referencia a los mecanismos europeos es suficiente. También hay que añadir que es un enfoque que simplemente plantea lo existente pero no aborda los retos de acción futuros, como es el hecho de que, desde 2012, el Programa Europeo se encuentre en revisión. En ese contexto debería reflexionarse y considerarse cuáles son los intereses específicos nacionales sobre esta cuestión a fin de conseguir su adecuada representación y defensa.

\section{Conclusión: Evaluación de la dimensión europea y recomendaciones de actuación}

Como conclusión al análisis desarrollado, tenemos que afirmar que la Administración española y la ESN viven, en buena medida, de espaldas al hecho de la integración europea, salvo excepciones tasadas. Hemos comprobado que, en líneas generales, la UE se encuentra ampliamente ausente en la ESN, dado que se han constatado carencias en casi todos los ámbitos y líneas de acción desde la triple perspectiva analizada.

En la ESN, la idea que se presenta de las fortalezas y debilidades españolas poco tiene en cuenta el carácter de miembro de la UE, tampoco se visualiza un proyecto claro de UE desde nuestro país, y finalmente, existen pocas referencias e incompletas a los instrumentos, políticas y organismos de la UE como medios al alcance de España para incrementar su seguridad. Salvo tres excepciones en las que se ha reparado, cuando el nivel político europeo aparece mencionado, lo es de una forma generalista, ambigua y respondiendo en algunos casos a un análisis del pasado pero que no expone las capacidades de la UE y resulta ajeno a los retos de futuro. Esto es especialmente relevante si tenemos en cuenta que el ámbito de acción de la UE debería ser utilizado como un instrumento más al alcance del Estado para construir seguridad, como en algunas ocasiones se ha hecho en el pasado con notable éxito. Especialmente resulta sorprendente que en muchos casos, la ESN obvie estrategias y actuaciones que de hecho se están desarrollando en el seno de la UE.

Por ello, sería recomendable integrar una perspectiva europea transversal en todos los ámbitos y líneas estratégicas de la ESN en su próxima revisión, y mientras tanto, aunque no figure nominalmente, en su implementación a través del Consejo de Seguridad Nacional. Vivir de espaldas al hecho de nuestra pertenencia a la UE hace que se desaprovechen posibilidades y recursos relevantes para promover la Seguridad Nacional. El primer paso debería ser reforzar la coordinación y coherencia de la acción nacional ante el nivel político europeo a través del órgano que tradicionalmente se ha ocupado de esta función, la Secretaría de Estado de la UE. Coordinación y coherencia que hoy día no son tan potentes como en los

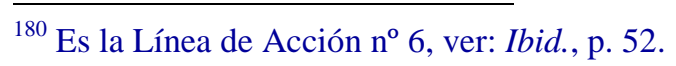


primeros años de la adhesión y que debe tener como uno de sus objetivos la integración de una dimensión de seguridad, a través de su asociación en el Consejo de Seguridad Nacional.

Finalmente, consideramos que ese reforzamiento de la dimensión europea de la Seguridad Nacional debería tener una fuerte inclinación hacia el futuro, que permita prepararse ante el cambio para poder incrementar las posibilidades de defensa del interés de España. Esto resulta fundamental en un momento en que estamos viviendo profundas transformaciones en el modelo político europeo, que no harán sino profundizarse en los próximos años. El Gobierno y el Parlamento español debe discutir y debatir su proyecto futuro de Unión Europea, y la mejor manera de defenderlo en las instancias encargadas de aprobarlo, teniendo en cuenta que en ese proyecto nos jugamos la seguridad y el futuro de nuestro país. 